\title{
Impact of Snow Grain Shape and Black Carbon-Snow Internal Mixing on Snow Optical Properties: Parameterizations for Climate Models $\mathscr{A}$
}

\author{
CENLin He \\ Department of Atmospheric and Oceanic Sciences, and Joint Institute for Regional Earth \\ System Science and Engineering, University of California, Los Angeles, Los Angeles, California, \\ and National Center for Atmospheric Research, Boulder, Colorado \\ YOSHI TAKANO AND KUO-NAN LIOU \\ Department of Atmospheric and Oceanic Sciences, and Joint Institute for Regional Earth \\ System Science and Engineering, University of California, Los Angeles, Los Angeles, California \\ PING YANG \\ Department of Atmospheric Sciences, Texas A\&M, College Station, Texas \\ QINBIN LI \\ Department of Atmospheric and Oceanic Sciences, and Joint Institute for Regional Earth System \\ Science and Engineering, University of California, Los Angeles, Los Angeles, California

\section{FEI CHEN} \\ National Center for Atmospheric Research, Boulder, Colorado
}

(Manuscript received 8 May 2017, in final form 4 August 2017)

\begin{abstract}
A set of parameterizations is developed for spectral single-scattering properties of clean and black carbon (BC)-contaminated snow based on geometric-optics surface wave (GOS) computations, which explicitly resolves BC-snow internal mixing and various snow grain shapes. GOS calculations show that, compared with nonspherical grains, volume-equivalent snow spheres show up to $20 \%$ larger asymmetry factors and hence stronger forward scattering, particularly at wavelengths $<1 \mu \mathrm{m}$. In contrast, snow grain sizes have a rather small impact on the asymmetry factor at wavelengths $<1 \mu \mathrm{m}$, whereas size effects are important at longer wavelengths. The snow asymmetry factor is parameterized as a function of effective size, aspect ratio, and shape factor and shows excellent agreement with GOS calculations. According to GOS calculations, the singlescattering coalbedo of pure snow is predominantly affected by grain sizes, rather than grain shapes, with higher values for larger grains. The snow single-scattering coalbedo is parameterized in terms of the effective size that combines shape and size effects, with an accuracy of $>99 \%$. Based on GOS calculations, BC-snow internal mixing enhances the snow single-scattering coalbedo at wavelengths $<1 \mu \mathrm{m}$, but it does not alter the snow asymmetry factor. The BC-induced enhancement ratio of snow single-scattering coalbedo, independent of snow grain size and shape, is parameterized as a function of $\mathrm{BC}$ concentration with an accuracy of $>99 \%$. Overall, in addition to snow grain size, both $\mathrm{BC}$-snow internal mixing and snow grain shape play critical roles in quantifying BC effects on snow optical properties. The present parameterizations can be conveniently applied to snow, land surface, and climate models including snowpack radiative transfer processes.
\end{abstract}

Supplemental information related to this paper is available at the Journals Online website: https://doi.org/10.1175/ JCLI-D-17-0300.s1.

Corresponding author: Cenlin He, cenlinhe@atmos.ucla.edu

\section{Introduction}

Snow is a key climate element that alters the Earth system through a strong snow albedo feedback (Qu and Hall 2014). Snow albedo greatly influences surface radiative balance via changing absorption of solar energy 
(Hansen and Nazarenko 2004; Jacobson 2004) and hydrology via changing snow sublimation and melting (Qian et al. 2009; Menon et al. 2010). A number of factors can affect snow albedo, including snow grain size (Wiscombe and Warren 1980; Aoki et al. 2011), grain shape (Liou et al. 2014; Dang et al. 2016), grain aggregating/ packing (He et al. 2017), and snow mass and density (Wiscombe and Warren 1980; Flanner et al. 2007), as well as environmental conditions such as solar zenith angle and cloud (Warren 1982). Moreover, impurities in snow can significantly reduce snow albedo (Warren and Wiscombe 1980, 1985; Flanner et al. 2007, 2009; He et al. 2014), among which black carbon (BC) is one of the most important light-absorbing aerosols (Bond et al. 2013; Li et al. 2017). Plenty of observations have shown strong snow albedo reduction resulting from $\mathrm{BC}$ deposition (Xu et al. 2009; Painter et al. 2013; Qian et al. 2015; Lee et al. 2017). Therefore, accurate estimates of snow albedo altered by impurities and associated climatic effects require comprehensive snow albedo modeling that integrates all the aforementioned key factors.

Climate models compute snow albedo via two major approaches. One is using detailed snow radiative transfer schemes, while the other is using empirical parameterizations derived from snow models. Previous studies have developed several parameterizations under different atmospheric conditions by assuming spherical snow grains externally mixed with impurities (e.g., Marshall and Warren 1987; Gardner and Sharp 2010; Aoki et al. 2011; Dang et al. 2015), which have been applied into global climate models (GCMs) partly for the consideration of computational efficiency. For example, Marshall and Warren (1987) parameterized snow albedo as a function of cloud transmittance, solar zenith angle, snow depth and grain size, BC concentration, and underlying surface albedo. Aoki et al. (2011) further included parameterizations of snow grain growth based on snow temperature and age. Recently, Dang et al. (2015) developed parameterizations of snow albedo reduction caused by impurities as a function of snow grain size and impurity content at multiple spectral bands.

On the other hand, an increasing number of efforts have been made to develop and couple sophisticated snow models into GCMs, where snow single-scattering properties (i.e., extinction efficiency, single-scattering albedo, and asymmetry factor) and environmental variables (e.g., solar zenith angle, incident solar flux, snow depth, and underlying surface albedo) are used as inputs to radiative transfer computations. For example, Wiscombe and Warren (1980) developed a detailed snow radiative transfer model to calculate spectral albedo of pure snow under different atmospheric conditions. They determined single-scattering properties of spherical snow grains by the Lorenz-Mie theory based on ice refractive index, snow grain size, and wavelength. Their following study (Warren and Wiscombe 1980) included $\mathrm{BC}$ contamination in the model by assuming external mixing of $\mathrm{BC}$ and snow spheres. On this basis, Flanner et al. (2007) further developed a multilayer snow radiative transfer model [Snow, Ice, and Aerosol Radiation (SNICAR) model] that accounts for both impurity content and snow grain growth under different conditions, which has been coupled into the Community Land Model (CLM) embedded in the Community Earth System Model (CESM), a widely used GCM.

However, two critical issues involving BC-snow internal mixing and nonspherical snow grains have not been fully accounted for in previous snow models or parameterizations, which could introduce large uncertainties in assessing BC-induced snow albedo effects. Multiple BC particles can be mixed within a single snow grain through various atmospheric processes, including rimming, aggregation, and accretion (Magono et al. 1979; Flanner et al. 2012). Flanner et al. (2012) assumed spherical snow grains and used a dynamic effective medium approximation to calculate the absorption cross section of BC internally mixed with snow and associated enhancement ratio relative to that of $\mathrm{BC}$ externally mixed with snow. They found a $43 \%-86 \%$ increase in $\mathrm{BC}$-induced snow albedo radiative forcing due to $\mathrm{BC}-$ snow internal mixing.

Nevertheless, observations have shown that nonspherical snow grains are ubiquitous in real snowpack (Dominé et al. 2003; Erbe et al. 2003). Many modeling efforts (e.g., Fu et al. 1999; Neshyba et al. 2003; Grenfell et al. 2005) have been made to investigate the shape effect of ice crystals on optical properties by using an effective size (e.g., equal-volume-to-area ratio), which works well for extinction efficiency and single-scattering albedo but is less accurate for the asymmetry factor $(\mathrm{Fu}$ 2007). Dang et al. (2016) used a physically based parameterization $(\mathrm{Fu} 2007)$ to compute asymmetry factor of nonspherical snow grains as a function of the aspect ratio and effective size. They showed that albedo of nonspherical snow grains is higher than that of snow spheres by $0.03-0.05$ in an opaque snowpack, without the consideration of $\mathrm{BC}-$ snow internal mixing. Liou et al. (2014) applied a geometric-optics surface wave (GOS) approach to deal with multiple BC particles internally mixed with nonspherical snow grains and found substantial impacts of both BC-snow internal mixing and snow grain shape on snow optical properties. Therefore, it is imperative to take into account these two key factors together in climate models in order to 
(a)

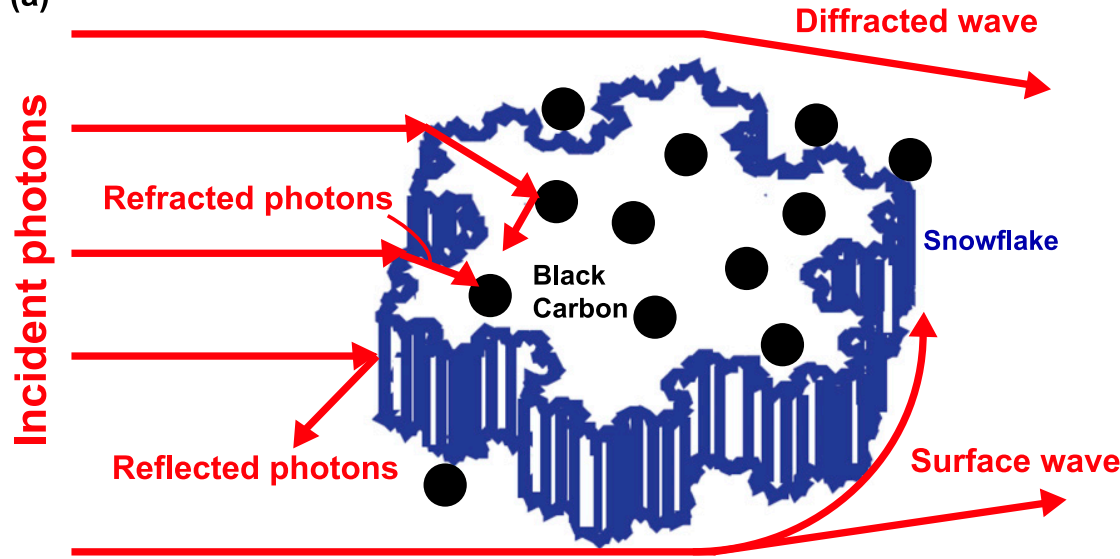

(b)

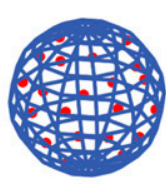

Sphere

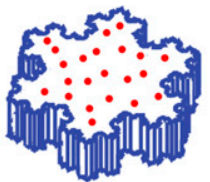

Koch Snowflake

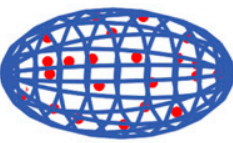

Spheroid

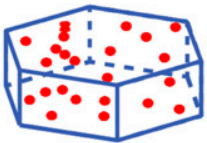

Hexagonal Plate

FIG. 1. (a) Illustration of the GOS method for interactions between light and nonspherical snow grains internally and externally mixed with multiple BC particles based on a Monte Carlo photon-tracing approach, accounting for reflection, refraction, diffraction, and surface wave. (b) Four types of snow grain shapes are used in this study, including sphere, Koch snowflake, spheroid, and hexagonal plate. Red dots are internally mixed BC particles.

accurately quantify BC-snow interactions and associated albedo effects.

The present study seeks to develop a set of parameterizations for spectral single-scattering properties of both clean and BC-contaminated snow by explicitly resolving BC-snow internal mixing and various snow grain shapes based on the GOS approach (Liou and Yang 2016). To the best of our knowledge, this is the first set of $\mathrm{BC}-$ snow parameterizations that account for the two critical factors simultaneously. The parameterizations can be easily incorporated into snow models (e.g., SNICAR), land surface models (e.g., CLM), and/or climate models (e.g., CESM) with snowpack radiative transfer schemes.

\section{Methods}

\section{a. GOS approach}

We use the GOS approach (Liou et al. 2011, 2014; He et al. 2014, 2015; Liou and Yang 2016) to compute single-scattering properties of snow grains internally mixed with multiple $\mathrm{BC}$ particles, which explicitly resolves nonspherical snow grain shapes and BC-snow mixing structures. Specifically, we construct snow grain structures in a 3D coordinate system and randomly distribute BC particles inside each snow grain through a stochastic procedure (Liou et al. 2014). To obtain singlescattering properties of BC-snow mixtures, we carry out light scattering and absorption computations using a Monte Carlo photon-tracing technique that accounts for geometric reflection and refraction, diffraction, and surface wave (shown in Fig. 1a), followed by a ray-byray integration method (Yang and Liou 1997). We further average the single-scattering properties of an ensemble of randomly orientated snow grains (mixed with BC) over all directions. Our previous studies have comprehensively evaluated and validated the accuracy of the GOS approach, including comparisons with laboratory measurements and the superposition T-matrix method for fresh BC aggregates and coated BC with complex structures (He et al. 2016; Takano et al. 2013), as well as the finite difference time domain (FDTD) method and discrete dipole approximation (DDA) for nonspherical ice crystals (Liou et al. 2011). Comparing with other optical methods, GOS can deal with a wider range of particle structures and sizes with a higher computational efficiency. More detailed descriptions of the GOS approach are provided in Liou and Yang (2016). 


\section{b. Theoretical calculations and parameterizations}

We perform GOS computations for clean and BCcontaminated snow with four grain shapes (see Fig. 1b), including sphere, Koch snowflake, spheroid, and hexagonal plate, which are used as typical examples to approximately represent observed snow grains in real snowpack (Dominé et al. 2003; Erbe et al. 2003). However, we note that these theoretical shapes may not completely capture complex snow structures from observations. We consider snow grain sizes (volumeequivalent sphere radii $r_{v}$ ) of 100,500 , and $1000 \mu \mathrm{m}$ for each grain shape with aspect ratios [i.e., ratio of grain width to length, following $\mathrm{Fu}$ (2007)] of 2.5, 2.5, 0.5, and 1.0 for Koch snowflake, hexagonal plate, spheroid, and sphere, respectively. Here, the aspect ratios for nonspherical snow grains, though arbitrarily determined, are generally consistent with observations (e.g., Garrett et al. 2015).

We define the effective diameter $D_{e}$ of a single snow grain as

$$
D_{e}=\frac{3 V_{\text {snow }}}{2 A_{\text {snow }}}
$$

or, equivalently,

$$
D_{e}=\frac{3}{2 \rho_{\text {ice }} \gamma}, \quad \text { with } \quad \gamma=\frac{A_{\text {snow }}}{\rho_{\text {ice }} V_{\text {snow }}},
$$

where $V_{\text {snow }}$ is the snow grain volume, $A_{\text {snow }}$ is the projected area of a snow grain averaged over all directions computed by GOS (see Table S1 in the supplemental material), $\rho_{\text {ice }}$ is the density of pure ice, and $\gamma$ is the projected-area-to-mass ratio (i.e., specific projected area). The specific projected area $\gamma$ is a fundamental parameter in determining absorption efficiency of nonspherical particles (Mitchell et al. 1996). Thus, the definition [Eq. (1)] of effective size in this study can be interpreted as the size of specific-projected-areaequivalent sphere. This definition has been widely used in both modeling studies (e.g., Foot 1988; Fu et al. 1999; Liou and Yang 2016) and satellite retrievals (e.g., Jin et al. 2008; Zege et al. 2008). Furthermore, compared with volume-equivalent sphere diameter $\left(D_{v}=2 r_{v}\right)$ and projected-area-equivalent sphere diameter $D_{p}$, it can be shown that $D_{e} \leq D_{v} \leq D_{p}$ (Fu et al. 1999). We further define a snow shape factor $f_{s, x}$ (where $x$ denotes sphere, hexagonal plate, spheroid, and Koch snowflake in this study) as the ratio of the specific-projected-areadefined effective diameter $D_{e}$ of a nonspherical grain to that of a spherical grain with the same volume, representing the effect of nonsphericity. Table 1 summarizes the effective diameters, shape factors, and aspect ratios for different snow shapes and sizes used in this study.

Another useful definition of effective diameter is the size of specific-surface-area-equivalent sphere $\left(D_{\mathrm{SSA}}=\right.$ $6\left(\rho_{\text {ice }} \mathrm{SSA}\right)^{-1}$, with SSA $=$ surface area divided by $\left.\rho_{\text {ice }} V_{\text {snow }}\right)$, which has been also commonly used in snow modeling (e.g., Flanner et al. 2007) and measurements (e.g., Painter et al. 2007). To link $D_{e}$ with $D_{\mathrm{SSA}}$, we calculate total surface area (see Table S1) and $D_{\mathrm{SSA}}$ (see Table 1) for different snow grain shapes used in this study. The results show that $D_{\mathrm{SSA}}=D_{e}$ for sphere, spheroid, and hexagonal plate because the projected area averaged over all directions is equal to one-fourth of the total surface area for these convex shapes. However, for Koch snowflake, $D_{\mathrm{SSA}}=0.544 D_{e}$, because the complex concave shape substantially increases total surface area and thus decreases $D_{\mathrm{SSA}}$.

Note that we develop parameterizations based on $D_{e}$ rather than $r_{v}$, while we use $r_{v}$ to define different calculation scenarios for comparisons of snow optical properties of four grain shapes with the same volume (i.e., same $r_{v}$ ). The comparisons directly show snow shape effects on optical properties for a fixed snow amount, which are particularly useful when snow mass/volume or snow water equivalent (SWE) is prognosed and tracked in models (e.g., Dutra et al. 2010; Niu et al. 2011) or retrieved from observations (e.g., Frei et al. 2012; Takala et al. 2011). However, the grain shape effect may be inflated using the same snow volume compared with using the same snow effective size.

For BC-contaminated snow, we randomly distribute a number of monodisperse BC spheres with an effective radius of $0.1 \mu \mathrm{m}$ (Schwarz et al. 2013) into each snow grain via a stochastic procedure developed by Liou et al. (2014). The number of BC particles in a snow grain is determined from $\mathrm{BC}$ mass concentration in snow, particle volumes of $\mathrm{BC}$ and snow, and densities of BC $\left(1.7 \mathrm{~g} \mathrm{~cm}^{-3}\right.$; Bond and Bergstrom 2006) and ice $\left(0.917 \mathrm{~g} \mathrm{~cm}^{-3}\right.$; Wiscombe and Warren 1980$)$. We consider BC mass concentrations $C_{\mathrm{BC}}$ of $0,1,10,50,100$, 500 , and $1000 \mathrm{ppb}$ (or $\mathrm{ng} \mathrm{g}^{-1}$ ) to represent low to high BC contamination based on observations (Qian et al. 2015). Schwarz et al. (2013) observed that a large BC diameter (around $1 \mu \mathrm{m}$ ) could also exist in snow, however, with a substantial uncertainty. The effect of BC size distribution on snow optical properties requires further investigation.

We use the GOS approach to calculate the spectral single-scattering properties of clean and $\mathrm{BC}$ contaminated snow in the solar spectrum $(0.2-5 \mu \mathrm{m}$, with an interval of $0.01 \mu \mathrm{m}$; hereinafter high-resolution GOS results), including extinction efficiency, singlescattering coalbedo $(1-\omega)$, and asymmetry factor $g$. 
TABLE 1. Snow properties used in ensemble calculations of snow single-scattering properties, with BC concentrations of $0,1,10,50,100$, 500 , and $1000 \mathrm{ng} \mathrm{g}^{-1}$ (or ppb) in snow for each scenario of snow shape and size.

\begin{tabular}{|c|c|c|c|c|c|}
\hline$r_{v}(\mu \mathrm{m})$ & Snow grain shape & $D_{e}(\mu \mathrm{m})$ & $D_{\mathrm{SSA}^{\mathrm{a}}}(\mu \mathrm{m})$ & $f_{s, x}{ }^{\mathrm{b}}$ & Aspect ratio \\
\hline \multirow[t]{4}{*}{100} & Sphere & 200.00 & 200.00 & 1.000 & 1.0 \\
\hline & Koch snowflake & 142.49 & 77.49 & 0.712 & 2.5 \\
\hline & Spheroid & 185.75 & 185.75 & 0.929 & 0.5 \\
\hline & Hexagonal plate & 157.58 & 157.58 & 0.788 & 2.5 \\
\hline \multirow[t]{4}{*}{500} & Sphere & 1000.0 & 1000.0 & 1.000 & 1.0 \\
\hline & Koch snowflake & 712.45 & 387.47 & 0.712 & 2.5 \\
\hline & Spheroid & 928.74 & 928.74 & 0.929 & 0.5 \\
\hline & Hexagonal plate & 787.91 & 787.91 & 0.788 & 2.5 \\
\hline \multirow[t]{4}{*}{1000} & Sphere & 2000.0 & 2000.0 & 1.000 & 1.0 \\
\hline & Koch snowflake & 1424.9 & 774.94 & 0.712 & 2.5 \\
\hline & Spheroid & 1857.5 & 1857.5 & 0.929 & 0.5 \\
\hline & Hexagonal plate & 1575.8 & 1575.8 & 0.788 & 2.5 \\
\hline
\end{tabular}

${ }^{\text {a }}$ The $D_{\mathrm{SSA}}$ is derived from snow grain surface area (see Table S1). The mathematical equations for calculating surface area of nonspherical snow grains are shown in the supplemental material.

${ }^{\mathrm{b}}$ Shape factor is defined as the ratio of the specific-projected-area-defined $D_{e}$ of a nonspherical snow grain to that of a spherical snow grain with the same grain volume, representing the effect of nonsphericity. Note that shape factor for the same type of snow grain shape could vary with aspect ratios.

The spectral refractive indices of snow and $\mathrm{BC}$ are from Warren and Brandt (2008) and Krekov (1993), respectively. Based on the high-resolution GOS results, we conduct multiple linear/nonlinear regressions to develop parameterizations for the single-scattering coalbedo and asymmetry factor of clean and BC-polluted snow as a function of snow grain size, grain shape, and/or $\mathrm{BC}$ concentration at different wavelength bands (see section 3 ). The mean values of single-scattering albedo $\bar{\omega}$ and asymmetry factor $\bar{g}$ in each wavelength band are calculated as follows (Fu 1996):

$$
\begin{gathered}
\bar{\omega}=\frac{\int \omega_{\lambda} \beta_{\lambda} s_{\lambda} d \lambda}{\int \beta_{\lambda} s_{\lambda} d \lambda} \text { and } \\
\bar{g}=\frac{\int g_{\lambda} \omega_{\lambda} \beta_{\lambda} s_{\lambda} d \lambda}{\int \omega_{\lambda} \beta_{\lambda} s_{\lambda} d \lambda},
\end{gathered}
$$

where $\lambda$ is the wavelength, $\beta_{\lambda}$ is the spectral extinction coefficient, $s_{\lambda}$ is the incident solar spectrum, and the limits of integrals are the edges of wavelength bands. We use the reference solar spectrum defined by the American Society for Testing and Materials (ASTM) (available at http://rredc.nrel.gov/solar/spectra/am1.5/; see also Fig. S1 in the supplemental material), which consists of direct and diffuse components under the COESA (1976) on a sun-facing, $37^{\circ}$-tilted surface, generated by the Simple Model of the Atmospheric Radiative Transfer of Sunshine (SMARTS) (Gueymard et al. 2002). The $37^{\circ}$ slope of the sun-facing tilted surface is selected to represent the mean condition of northern midlatitude regions such as the contiguous United States (Gueymard et al. 2002). For other latitudes with similar atmospheric conditions, the incident solar spectrum is proportional to that used here, which does not affect the mean single-scattering properties determined in this study.

We do not parameterize snow extinction efficiency, which is very close to a value of 2 for a large size parameter $\left(\pi D_{e} / \lambda>100\right.$ in this study) of snow in the solar spectrum (Liou 2002) and barely affected by snow grain shape and inclusion of BC particles (Liou et al. 2014). The extinction efficiency can be computed by assuming a pure snow sphere with the same projected area of its nonspherical counterpart based on the Lorenz-Mie theory (Wiscombe and Warren 1980) or the geometric optics method (Liou 2002). For direct application to climate models, we also provide lookup tables (Tables S2-S4 in the supplemental material) for spectral extinction efficiencies of different snow shapes and sizes used in this study. The deviations to a value of 2 are rather small $(<3 \%)$ and further decrease as grain sizes increase. This is consistent with the conclusion in Wiscombe and Warren (1980), which showed that snow extinction efficiency departure from 2 is $<6 \%$ for a radius of $50 \mu \mathrm{m}$ and reduces to $<1 \%$ for a radius of $1000 \mu \mathrm{m}$.

Although we implicitly assume monodisperse snow size distributions, the resonance artifacts in light absorption and scattering computations are negligible, because of the large snow size parameter and the effect from averaging optical properties of an ensemble of randomly orientated snow grains over all directions. 


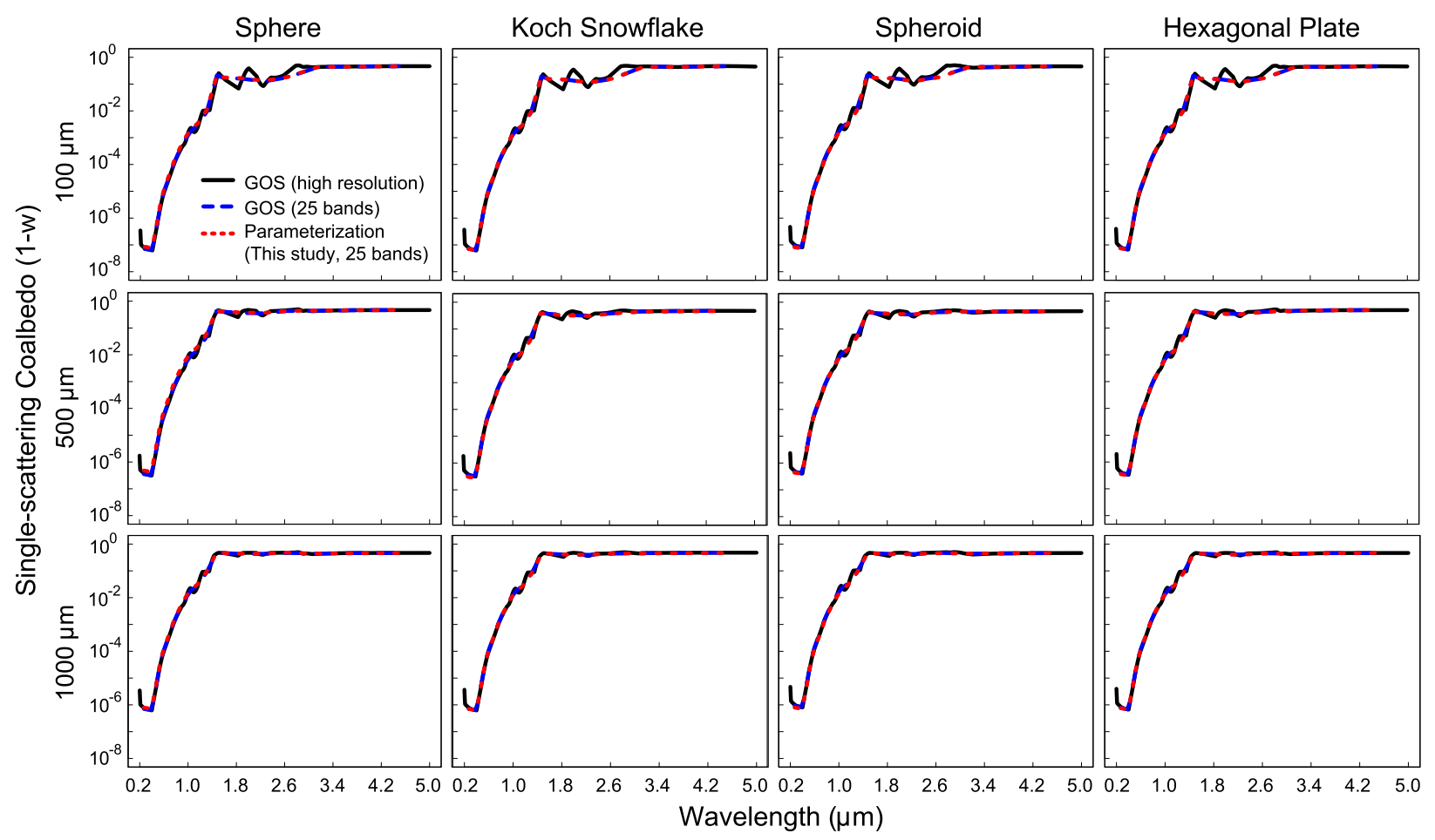

FIG. 2. Spectral single-scattering coalbedo $(1-\omega)$ of pure snow from GOS calculations at a high wavelength resolution (black solid line) and a 25-band resolution (blue dashed line) as well as a new parameterization [Eq. (4), following Liou et al.'s (2013) formulation] from this study at a 25-band resolution (red dotted line) for (left) sphere, (center left) Koch snowflake, (center right) spheroid, and (right) hexagonal plate with $r_{v}$ of (top) 100 , (middle) 500, and (bottom) $1000 \mu \mathrm{m}$. See text and Table 1 for details. Note that the blue and red lines overlap with each other owing to very close values in all panels.

However, we realize that snow grains have polydisperse size distributions in reality (Nakamura et al. 2001). Thus, given different sensitivities of snow optical properties to its size (see sections 3 and 4), assuming monodisperse size distribution may introduce nontrivial uncertainty to calculations of snow single-scattering coalbedo at wavelengths $<2.5 \mu \mathrm{m}$ and asymmetry factor at wavelengths of $1.5-3.0 \mu \mathrm{m}$. Different assumptions of snow size distribution can also affect BC-snow internal mixing by altering the number of $\mathrm{BC}$ particles contained in each snow grain. We note that it is important to account for polydisperse size distributions for nonspherical snow grains and aerosol-snow internal mixing, which will be investigated in future work.

\section{Results and discussion}
a. Grain size and shape effects on optical properties of pure snow

\section{1) Single-sCATtering COALBEDo}

Figure 2 shows the spectral single-scattering coalbedo of pure snow with shapes of Koch snowflake, hexagonal plate, spheroid, and sphere as well as $r_{v}$ of 100,500, and $1000 \mu \mathrm{m}$. The single-scattering coalbedo increases by several orders of magnitude from visible to infrared (IR) wavelengths, with the minimum $\left(\sim 10^{-7}\right)$ at approximately $0.4 \mu \mathrm{m}$ and the maximum $(0.4-0.5)$ at wavelengths $>\sim 1.5 \mu \mathrm{m}$ for all snow shapes and sizes. This is primarily because of the spectral characteristics of snow imaginary index of refraction (Warren and Brandt 2008), which reaches the lowest value at 0.2$0.4-\mu \mathrm{m}$ wavelengths and increases at $0.4-3 \mu \mathrm{m}$. There are some fluctuations in snow single-scattering coalbedo between 1.5 and $2.5 \mu \mathrm{m}$ caused by the wiggling imaginary index of refraction at these wavelengths (Warren and Brandt 2008), which becomes much smaller as snow size increases from 100 to $1000 \mu \mathrm{m}$. Figure S2 in the supplemental material shows that larger snow grains (e.g., $r_{v}=1000 \mu \mathrm{m}$ for old snow) has up to one order of magnitude higher single-scattering coalbedo than smaller grains (e.g., $r_{v}=100 \mu \mathrm{m}$ for fresh snow), particularly at wavelengths $<2.5 \mu \mathrm{m}$, suggesting a much stronger light absorption and hence lower albedo for larger snow grains, as revealed by previous studies (Wiscombe and Warren 1980; Flanner et al. 2007). Among the four snow grain shapes, spheroids and 
TABLE 2. Coefficients for the parameterization [Eq. (4)] of single-scattering coalbedo of pure snow.

\begin{tabular}{|c|c|c|c|c|}
\hline Wavelength bands ${ }^{\mathrm{a}}(\mu \mathrm{m})$ & $a_{0}$ & $a_{1}$ & $a_{2}$ & $a_{3}$ \\
\hline $0.25-0.30$ & $-1.69659 \times 10^{1}$ & $3.75204 \times 10^{-3}$ & $-1.51852 \times 10^{-6}$ & $1.85365 \times 10^{-10}$ \\
\hline $0.30-0.33$ & $-1.70023 \times 10^{1}$ & $3.76191 \times 10^{-3}$ & $-1.53154 \times 10^{-6}$ & $1.89840 \times 10^{-10}$ \\
\hline $0.33-0.36$ & $-1.70308 \times 10^{1}$ & $3.76964 \times 10^{-3}$ & $-1.54174 \times 10^{-6}$ & $1.93344 \times 10^{-10}$ \\
\hline $0.36-0.40$ & $-1.70826 \times 10^{1}$ & $3.78371 \times 10^{-3}$ & $-1.56030 \times 10^{-6}$ & $1.99723 \times 10^{-10}$ \\
\hline $0.40-0.44$ & $-1.64456 \times 10^{1}$ & $3.79579 \times 10^{-3}$ & $-1.57662 \times 10^{-6}$ & $2.05463 \times 10^{-10}$ \\
\hline $0.44-0.48$ & $-1.53350 \times 10^{1}$ & $3.80249 \times 10^{-3}$ & $-1.58586 \times 10^{-6}$ & $2.08770 \times 10^{-10}$ \\
\hline $0.48-0.52$ & $-1.42127 \times 10^{1}$ & $3.80685 \times 10^{-3}$ & $-1.59164 \times 10^{-6}$ & $2.10757 \times 10^{-10}$ \\
\hline $0.52-0.57$ & $-1.30367 \times 10^{1}$ & $3.81103 \times 10^{-3}$ & $-1.59719 \times 10^{-6}$ & $2.12662 \times 10^{-10}$ \\
\hline $0.57-0.64$ & $-1.19078 \times 10^{1}$ & $3.81482 \times 10^{-3}$ & $-1.60229 \times 10^{-6}$ & $2.14467 \times 10^{-10}$ \\
\hline $0.64-0.69$ & $-1.10597 \times 10^{1}$ & $3.81806 \times 10^{-3}$ & $-1.60707 \times 10^{-6}$ & $2.16194 \times 10^{-10}$ \\
\hline $0.69-0.75$ & $-1.02251 \times 10^{1}$ & $3.82275 \times 10^{-3}$ & $-1.61478 \times 10^{-6}$ & $2.18961 \times 10^{-10}$ \\
\hline $0.75-0.78$ & $-9.59592 \times 10^{0}$ & $3.82649 \times 10^{-3}$ & $-1.62122 \times 10^{-6}$ & $2.21257 \times 10^{-10}$ \\
\hline $0.78-0.87$ & $-8.88669 \times 10^{0}$ & $3.83256 \times 10^{-3}$ & $-1.63061 \times 10^{-6}$ & $2.24358 \times 10^{-10}$ \\
\hline $0.87-1.00$ & $-7.71578 \times 10^{0}$ & $3.83931 \times 10^{-3}$ & $-1.65229 \times 10^{-6}$ & $2.32268 \times 10^{-10}$ \\
\hline $1.00-1.10$ & $-6.79936 \times 10^{0}$ & $3.85268 \times 10^{-3}$ & $-1.68290 \times 10^{-6}$ & $2.42830 \times 10^{-10}$ \\
\hline $1.10-1.19$ & $-6.39743 \times 10^{0}$ & $3.86713 \times 10^{-3}$ & $-1.72148 \times 10^{-6}$ & $2.56371 \times 10^{-10}$ \\
\hline $1.19-1.41$ & $-5.25170 \times 10^{0}$ & $3.89281 \times 10^{-3}$ & $-1.83974 \times 10^{-6}$ & $2.99312 \times 10^{-10}$ \\
\hline $1.41-1.53$ & $-1.92743 \times 10^{0}$ & $2.34182 \times 10^{-3}$ & $-1.62625 \times 10^{-6}$ & $3.71728 \times 10^{-10}$ \\
\hline $1.53-1.64$ & $-2.22997 \times 10^{0}$ & $2.86496 \times 10^{-3}$ & $-1.94925 \times 10^{-6}$ & $4.41586 \times 10^{-10}$ \\
\hline $1.64-2.13$ & $-2.24402 \times 10^{0}$ & $2.56942 \times 10^{-3}$ & $-1.66880 \times 10^{-6}$ & $3.69240 \times 10^{-10}$ \\
\hline $2.13-2.38$ & $-2.58434 \times 10^{0}$ & $3.22613 \times 10^{-3}$ & $-2.11600 \times 10^{-6}$ & $4.71654 \times 10^{-10}$ \\
\hline $2.38-2.91$ & $-2.22349 \times 10^{0}$ & $3.01487 \times 10^{-3}$ & $-2.11400 \times 10^{-6}$ & $4.89057 \times 10^{-10}$ \\
\hline $2.91-3.42$ & $-8.17662 \times 10^{-1}$ & $-9.12327 \times 10^{-6}$ & $3.45201 \times 10^{-8}$ & $-1.59533 \times 10^{-11}$ \\
\hline $3.42-4.00$ & $-8.34518 \times 10^{-1}$ & $1.21803 \times 10^{-4}$ & $-7.79873 \times 10^{-8}$ & $1.41537 \times 10^{-11}$ \\
\hline $4.00-4.99$ & $-7.78631 \times 10^{-1}$ & $3.13347 \times 10^{-5}$ & $-1.26599 \times 10^{-8}$ & $-4.40475 \times 10^{-13}$ \\
\hline
\end{tabular}

${ }^{\text {a }}$ Wavelength bands are based on $\mathrm{Fu}(1996)$.

hexagonal plates tend to have slightly $(5 \%-30 \%)$ larger single-scattering coalbedo and hence stronger light absorption at wavelength $<1.5 \mu \mathrm{m}$ than spheres (Fig. S3 in the supplemental material), while Koch snowflakes have the lowest single-scattering coalbedo at $0.3-3.0-\mu \mathrm{m}$ wavelengths (Fig. S3). However, we should note that snow single-scattering coalbedo is predominantly affected by grain size rather than grain shape (see section 4 ), in line with the results in previous studies (Jin et al. 2008).

Liou et al. (2013) developed a parameterization to link the single-scattering coalbedo of cirrus clouds with hexagonal-plate shapes to their effective grain sizes, illustrating an exponential-polynomial relationship. We find that both snow shape and size effects on singlescattering coalbedo can be explained using the effective grain size. Thus, following Liou et al.'s (2013) formulation, we develop a parameterization for the singlescattering coalbedo of pure snow with different grain shapes and sizes based on the theoretical GOS calculations as follows:

$$
1-\omega=\exp \left(a_{0}+a_{1} D_{e}+a_{2} D_{e}^{2}+a_{3} D_{e}^{3}\right),
$$

where $D_{e}(\mu \mathrm{m})$ is the effective snow diameter defined in Eq. (1) and $a_{i}$ (where $i=0-3$ ) is the wavelength-dependent parameterization coefficient. The effective diameter implicitly contains snow shape information (Table 1). We provide a dataset (Table 2) of the parameterization coefficients $\left[a_{i}\right.$ in Eq. (4)] at 25 wavelength bands within $0.25-5 \mu \mathrm{m}$. The 25-band type follows Fu (1996). Figure 2 shows that the parameterization results closely match with the GOS calculations for all snow sizes and shapes across the spectrum, with a normalized mean bias (NMB) of $0.56 \%$ and a coefficient of determination $R^{2}$ of 0.9996 (see Fig. 3a). Overall, the accuracy of this parameterization is higher than $99 \%$, making it a good candidate for implementation in snow models.

In addition, $\mathrm{Fu}$ (1996) used a slightly different formulation from that in Liou et al. (2013) for the singlescattering coalbedo of cirrus clouds with hexagonalcolumn shapes, shown as follows:

$$
1-\omega=a_{0}^{\prime}+a_{1}^{\prime} D_{e}+a_{2}^{\prime} D_{e}^{2}+a_{3}^{\prime} D_{e}^{3} .
$$

As another parameterization option for the snow singlescattering coalbedo, we also provide a dataset of parameterization coefficients $\left[a_{i}^{\prime}\right.$ in Eq. (5), where $\left.i=0-3\right]$ based on Fu's (1996) formulation (see Table S5 in the supplemental material). Figure S4 in the supplemental material shows a good agreement between the 

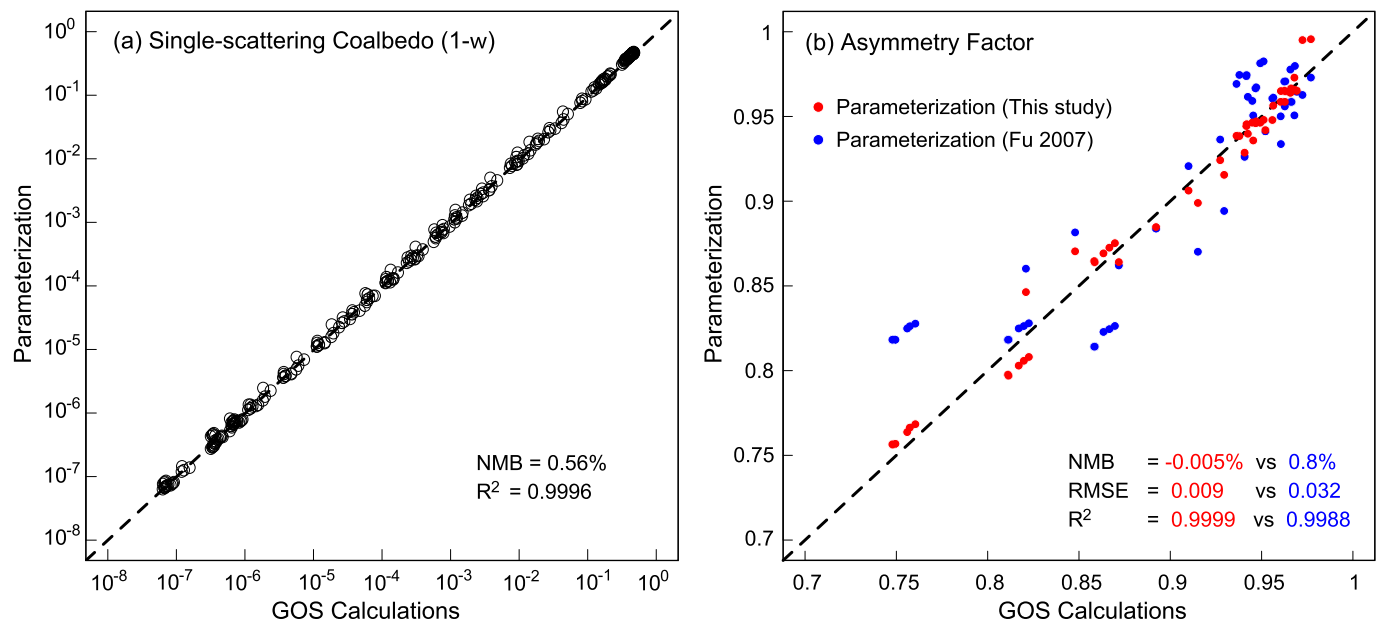

FIG. 3. (a) Comparison for single-scattering coalbedo $(1-\omega)$ of pure snow from GOS calculations and a new parameterization [Eq. (4), following Liou et al.'s (2013) formulation] from this study at 25 wavelength bands in the solar spectrum (see Table 2) for sphere, Koch snowflake, spheroid, and hexagonal plate with $r_{v}$ of 100,500 , and $1000 \mu \mathrm{m}$. (b) Comparison for asymmetry factor of pure snow from GOS calculations and a new parameterization [Eqs. (6) and (7)] from this study (red dots) as well as a parameterization from $\mathrm{Fu}$ (2007) (blue dots) at six wavelength bands in the solar spectrum (see Table 3) for Koch snowflake, spheroid, and hexagonal plate with $r_{v}$ of 100,500 , and $1000 \mu \mathrm{m}$. Also shown are the NMB, RMSE, and $R^{2}$ for both parameterizations. The dashed lines in (a) and (b) are 1:1 ratio lines.

parameterization results and GOS calculations, with an NMB of $-2.3 \%$ and a $R^{2}$ of 0.998 (Fig. S5 in the supplemental material), except for a $50 \%$ underestimate at $1.5-2.5 \mu \mathrm{m}$ for small grains $\left(r_{v}=100 \mu \mathrm{m}\right)$. Thus, this optional parameterization [Eq. (5)] also has a high overall accuracy $(\sim 97 \%)$.

\section{2) ASYMMETRY FACTOR}

Figure 4 shows the spectral asymmetry factor of pure snow with shapes of Koch snowflake, hexagonal plate, and spheroid as well as $r_{v}$ of 100,500 , and $1000 \mu \mathrm{m}$. We find that grain size has a rather small $(<0.5 \%)$ effect on snow asymmetry factor at wavelengths $<1 \mu \mathrm{m}$ for all four shapes, whereas at wavelengths $>1 \mu \mathrm{m}$, a larger snow grain lead to a higher asymmetry factor (Figs. 4, and S6 in the supplemental material). Compared with nonspherical grains, snow spheres with the same volume show up to $20 \%$ larger asymmetry factors and hence stronger forward scattering at wavelengths $<\sim 2.6 \mu \mathrm{m}$ (Fig. S6), consistent with previous studies (Liou et al. 2014; Dang et al. 2016), while the differences are small $(<2 \%)$ at larger wavelengths (Fig. S6). As a result, assuming only spherical grains in snow models could overestimate snow forward scattering and thus underestimate snow albedo, particularly at visible and near-infrared (NIR) wavelengths, compared to the real snowpack often with nonspherical snow grains (Dominé et al. 2003; Erbe et al. 2003). This further suggests that spherical snow grains, via stronger forward scattering, could enhance $\mathrm{BC}$ absorption in snowpack, resulting in a larger BC-induced snow albedo effect, relative to nonspherical snow grains. He et al. (2014) found that spherical snow grain leads to a $20 \%-40 \%$ stronger BCinduced snow albedo reduction than Koch snowflake. Dang et al. (2016) developed a scaling factor (1.1-2.5) to match the spectral albedo of a snowpack with snow spheres to that of nonspherical grains. We further find that, among nonspherical grains, spheroids tend to have the highest asymmetry factors and Koch snowflakes have the lowest, with the largest differences at wavelengths $<1 \mu \mathrm{m}$ (Fig. 4).

$\mathrm{Fu}$ (2007) developed a parameterization for the asymmetry factor of ice crystals as a function of the aspect ratio and effective grain size for cirrus cloud with hexagonal-column shapes and smooth or rough surfaces. In this study, we assume snow grains with smooth surfaces, which have been widely observed (Dominé et al. 2003; Erbe et al. 2003) and can be formed through snow metamorphism processes such as vapor transfer, melting-refreezing, compaction, and liquid processes (Flanner et al. 2012). Jin et al. (2008) found that surface roughness of snow grains has a very small effect on asymmetry factor and albedo. Using Fu's (2007) parameterization, we find that the results capture the GOS calculations for hexagonal plates reasonably well but systematically overestimate (underestimate) the asymmetry factor of Koch snowflakes (spheroids) at wavelengths $<2.6 \mu \mathrm{m}$ for all the sizes (Fig. 4), 


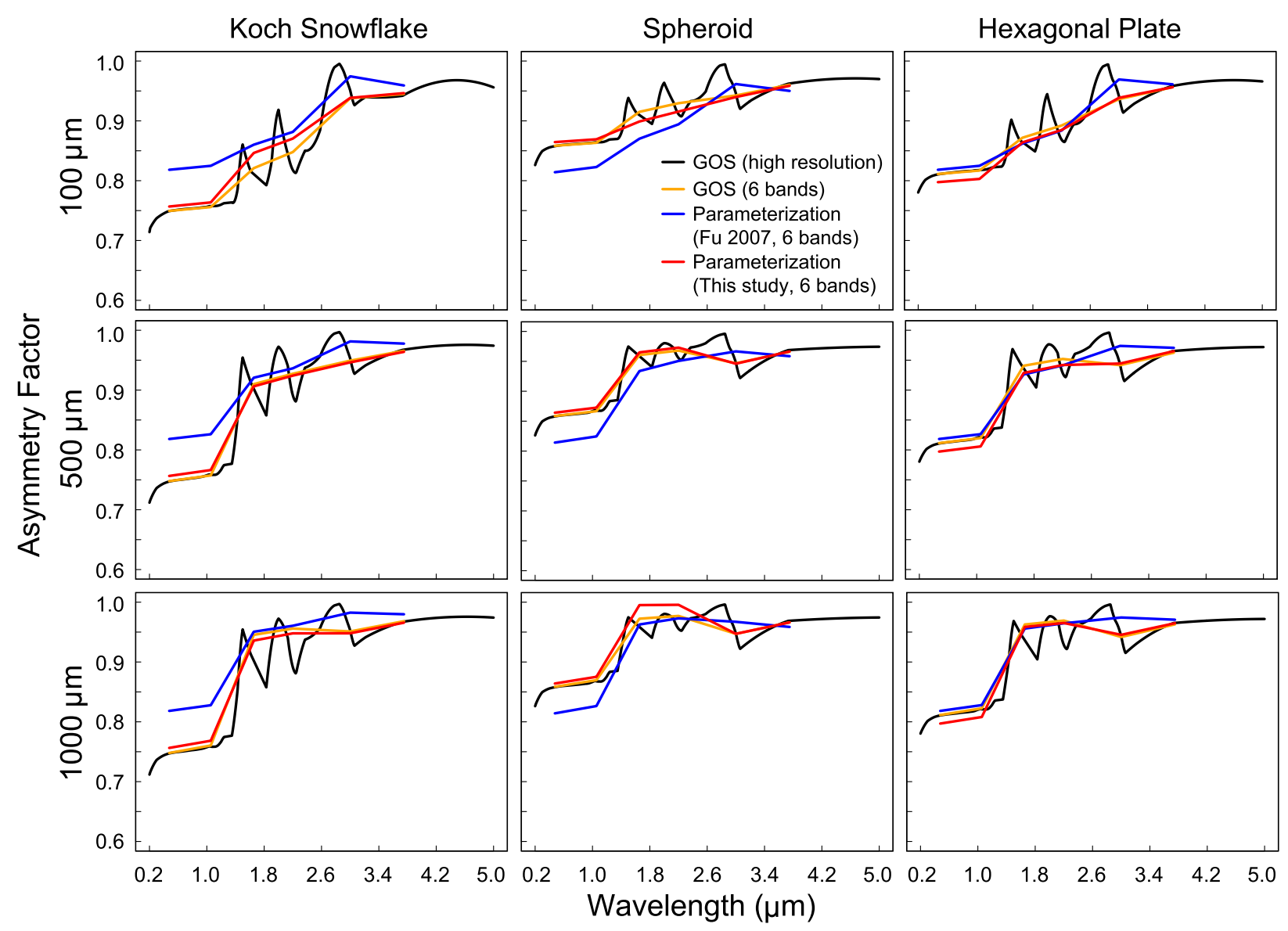

FIG. 4. Spectral asymmetry factor of pure snow from GOS calculations at a high wavelength resolution (black) and a six-band resolution (orange) as well as a new parameterization [Eqs. (6) and (7)] from this study (red) and the parameterization from Fu (2007) (blue) at a sixband resolution for (left) Koch snowflake, (center) spheroid, and (right) hexagonal plate with $r_{v}$ of (top) 100, (middle) 500, and (bottom) $1000 \mu \mathrm{m}$. Asymmetry factors of spheres are not shown because the parameterizations here [this study and Fu (2007)] are only applicable to nonspherical snow grains. Instead, the asymmetry factors of spheres from GOS calculations at a high wavelength resolution are shown in Fig. S6.

particularly at wavelengths $<1 \mu \mathrm{m}$. This suggests that information about grain shapes deviating from hexagonal plates/columns should also be included in the parameterization. Thus, extending Fu's (2007) formulation, we develop a new parameterization for the asymmetry factor of nonspherical snow grains by including an additional parameter, shape factor $f_{s, x}$ (see section $2 \mathrm{~b}$ and Table 1 ). The new formulation is as follows:

$$
\begin{aligned}
g_{\text {new }} & =g_{\mathrm{Fu} 07} C_{g} \text { and } \\
C_{g} & =b_{0}\left(\frac{f_{s, x}}{f_{s, \text { hex }}}\right)^{b_{1}} D_{e}^{b_{2}},
\end{aligned}
$$

where $g_{\mathrm{Fu} 07}$ is the asymmetry factor computed from Fu's (2007) parameterization and $C_{g}$ is the correction factor developed in this study. The coefficients $b_{i}$ (where $i=0-2$ ) are the wavelength-dependent parameterization coefficients. The variable $f_{s, \text { hex }}$ is the shape factor of hexagonal plate, which is used as a reference/normalizing factor here, because Fu's (2007) parameterization is based on hexagonal shape. Following Fu (2007), we provide a dataset (Table 3) of the parameterization coefficients $\left[b_{i}\right.$ in Eq. (7)] at six wavelength bands within $0.25-4 \mu \mathrm{m}$. We note that $b_{2}$ is two orders of magnitude smaller than $b_{1}$, indicating that the correction factor is dominated by the impact of grain shape rather than size. We also note that this new parameterization is based on empirical statistical analyses.

The new parameterization results in a good agreement with the GOS calculations for all snow grain shapes and sizes (Fig. 4), except for a slight overestimate at $1.5-2.5-\mu \mathrm{m}$ wavelengths for spheroids with a $r_{v}$ of $1000 \mu \mathrm{m}$ and Koch snowflakes with $r_{v}$ of $100 \mu \mathrm{m}$. Compared with Fu's (2007) parameterization, the new 
TABLE 3. Coefficients for the parameterization [Eq. (7)] of asymmetry factor of pure snow.

\begin{tabular}{cccr}
\hline \hline $\begin{array}{c}\text { Wavelength } \\
\text { bands }^{\mathrm{a}}(\mu \mathrm{m})\end{array}$ & \multicolumn{1}{c}{$b_{0}$} & $b_{1}$ & \multicolumn{1}{c}{$b_{2}$} \\
\hline $0.25-0.70$ & $9.76029 \times 10^{-1}$ & $5.21042 \times 10^{-1}$ & $-2.66792 \times 10^{-4}$ \\
$0.70-1.41$ & $9.67798 \times 10^{-1}$ & $4.96181 \times 10^{-1}$ & $1.14088 \times 10^{-3}$ \\
$1.41-1.90$ & $1.00111 \times 10^{0}$ & $1.83711 \times 10^{-1}$ & $2.37011 \times 10^{-4}$ \\
$1.90-2.50$ & $1.00224 \times 10^{0}$ & $1.37082 \times 10^{-1}$ & $-2.35905 \times 10^{-4}$ \\
$2.50-3.50$ & $9.64295 \times 10^{-1}$ & $5.50598 \times 10^{-2}$ & $8.40449 \times 10^{-4}$ \\
$3.50-4.00$ & $9.97475 \times 10^{-1}$ & $8.48743 \times 10^{-2}$ & $-4.71484 \times 10^{-4}$
\end{tabular}

${ }^{\mathrm{a}}$ Wavelength bands are based on $\mathrm{Fu}(2007)$.

parameterization reduces the NMB from $0.8 \%$ to $-0.005 \%$ and the root-mean-square error (RMSE) from 0.032 to 0.009 (see Fig. 3b). This parameterization can be easily applied in different snow models to assess shape effects on snow albedo. We note that the spectral resolution of the asymmetry factor parameterization is relatively coarse, but it captures the main features of snow asymmetry factor reasonably well, except for the wiggling part at $1.5-3.0 \mu \mathrm{m}$. In addition, the parameterizations from this study and Fu (2007) are only applicable for nonspherical snow grains, rather than spheres. The asymmetry factor of spherical snow grains
(Fig. S6) can be computed from the Lorenz-Mie theory or GOS.

\section{b. Internal mixing of $B C$ and snow with different shapes and sizes}

\section{1) BC EFFECTS ON SNOW OPTICAL PROPERTIES}

Figure 5 shows the spectral single-scattering coalbedo for BC-contaminated snow with $\mathrm{BC}$ concentrations of 0 , $1,10,50,100,500$, and $1000 \mathrm{ppb}$. BC contamination primarily enhances snow single-scattering coalbedo at wavelengths $<1 \mu \mathrm{m}$ for all the snow sizes and shapes, particularly at visible wavelengths, with a larger singlescattering coalbedo for a higher BC concentration, whereas $\mathrm{BC}$ has a negligible impact at wavelengths $>1 \mu \mathrm{m}$. We find that $\mathrm{BC}$-snow internal mixing has no effects on the snow asymmetry factor (Fig. S6), consistent with the conclusion in previous studies (Liou et al. 2014). Thus, we only discuss and parameterize the impact of BC on snow single-scattering coalbedo at wavelengths $<1 \mu \mathrm{m}$ hereinafter.

We calculate the enhancement ratio $R_{1-\omega}$ of snow single-scattering coalbedo caused by BC-snow internal mixing, which is defined as the ratio of single-scattering

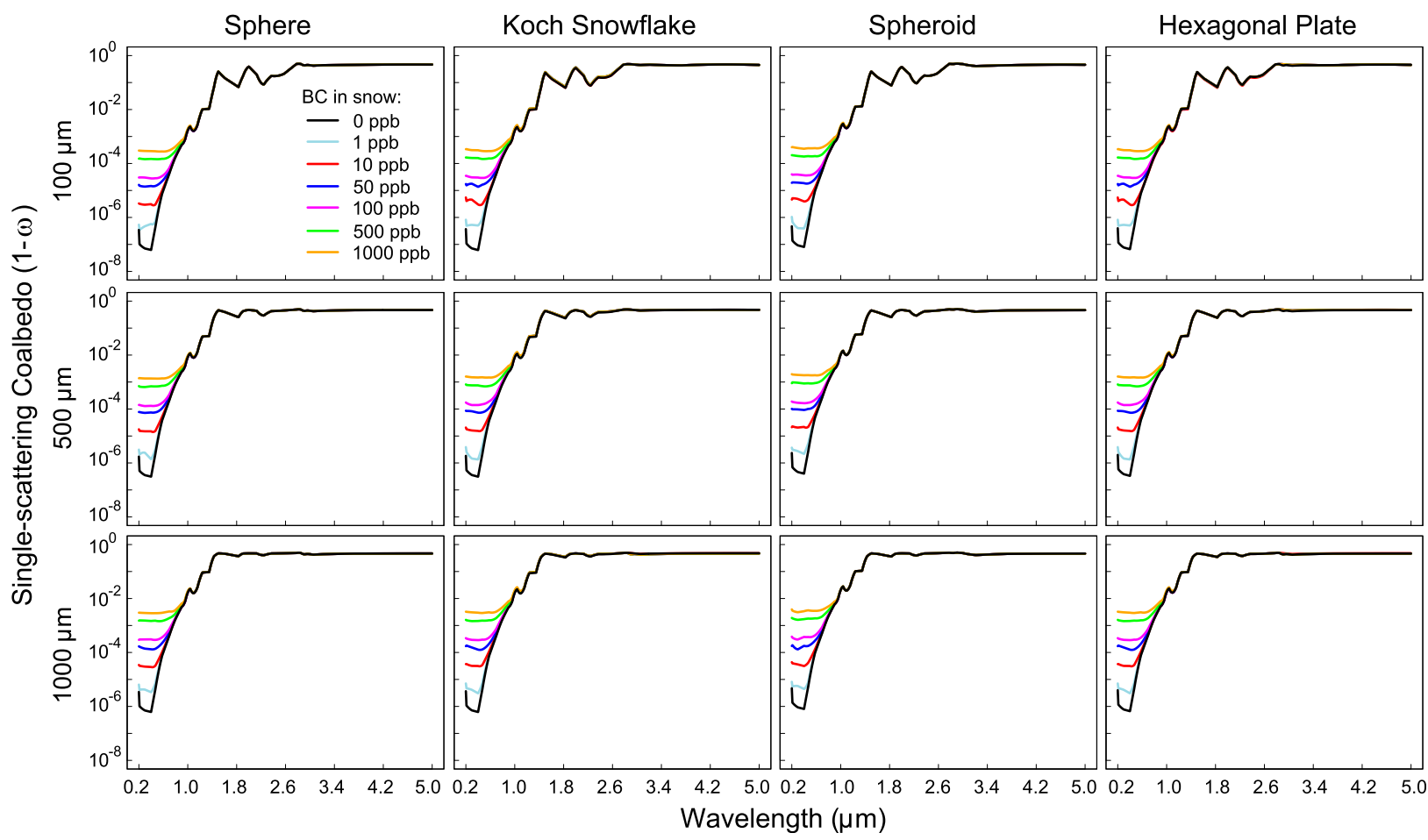

FIG. 5. Spectral single-scattering coalbedo $(1-\omega)$ of pure snow (black) and BC-contaminated snow with BC concentrations of 1 (light blue), 10 (red), 50 (blue), 100 (magenta), 500 (green), and $1000 \mathrm{ppb}$ (orange), for (left) sphere, (center left) Koch snowflake, (center right) spheroid, and (right) hexagonal plate with $r_{v}$ of (top) 100, (middle) 500, and (bottom) $1000 \mu \mathrm{m}$. The results are from GOS calculations at a high wavelength resolution in the solar spectrum. 

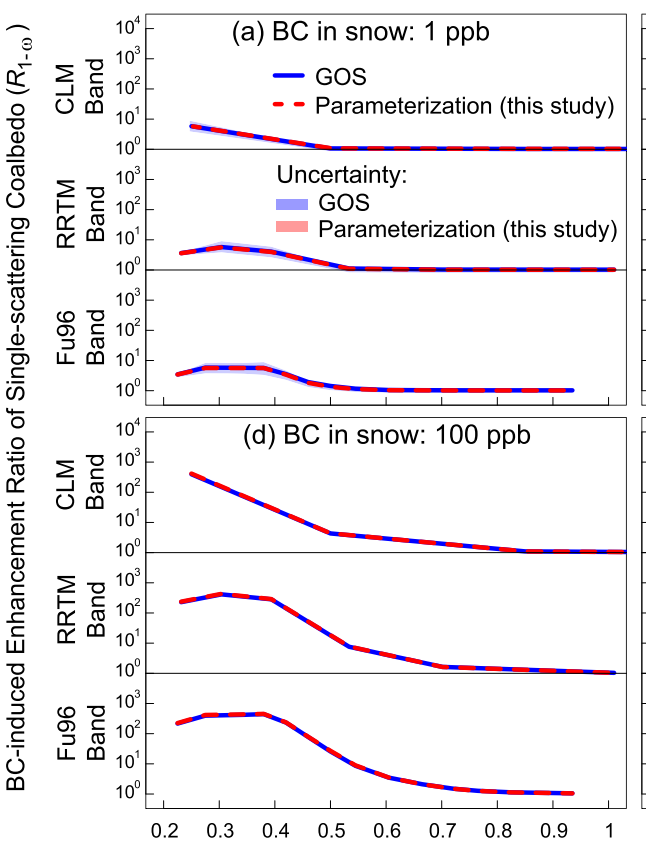
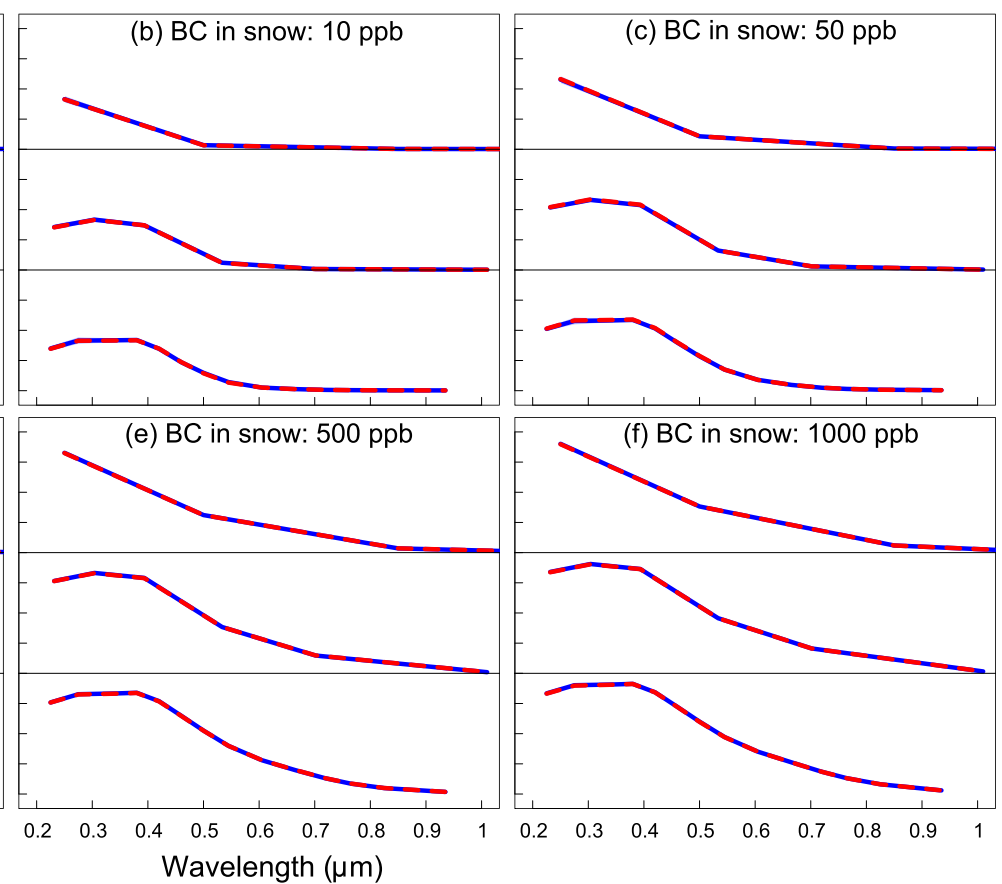

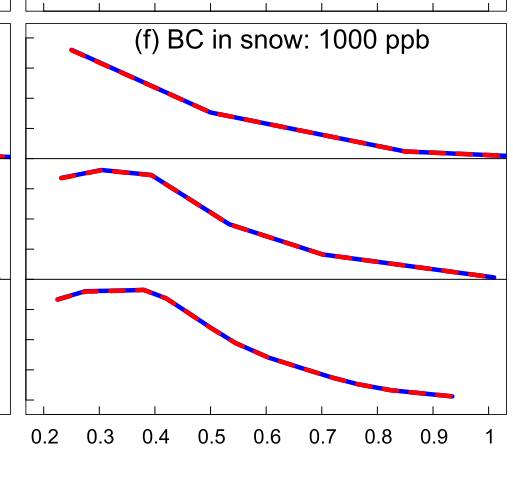

FIG. 6. Spectral BC-induced enhancement ratio of snow single-scattering coalbedo $\left[R_{1-\omega}\right.$ in Eq. (8b)] from GOS calculations (blue solid lines) and a new parameterization [red dashed lines; Eq. (8b)] from this study for (a)-(f) six different BC concentrations in snow. For each panel, the results for three types of band divisions at $0.2-1.0-\mu \mathrm{m}$ wavelengths are shown, including the Fu96 band, RRTM band, and CLM band. Results for wavelengths $>1 \mu \mathrm{m}$ are not shown owing to negligible BC effects. Also shown are $95 \%$ uncertainty ranges (shaded area) associated with GOS calculations (blue) and the new parameterization (red) due to different snow grain shapes and sizes, which is calculated as described in section 4. See text for details. Note that the blue and red lines are overlapped with each other in all panels as a result of very close values, and the uncertainties (shaded areas) are very small (i.e., negligible shape and size effects on $R_{1-\omega}$; see also Fig. S7).

coalbedo for BC-contaminated snow to that for pure snow. We find that the spectral BC-induced enhancement ratio is a function of $\mathrm{BC}$ concentration but independent of snow grain size and shape (Fig. S7 in the supplemental material and Fig. 6). The enhancement ratio reaches the maximum at $0.2-0.4 \mu \mathrm{m}$ owing to a very strong $\mathrm{BC}$ absorption and a very weak snow absorption at these wavelengths and quickly decreases to 1.0 from 0.4 to $1 \mu \mathrm{m}$ (Figs. 6 and S7). The maximum enhancement ratio (at $0.2-0.4 \mu \mathrm{m}$ ) is 10 for $1 \mathrm{ppb} \mathrm{BC}$ in snow and increases to $>1000$ for $1000 \mathrm{ppb}$ $\mathrm{BC}$. We further quantitatively link the $\mathrm{BC}$-induced enhancement ratio to the $\mathrm{BC}$ concentration in snow [see section $3 b(2)]$.

We should note that although the effects of snow grain shape and size are negligible for the BC-induced enhancement ratio, they significantly affect singlescattering coalbedo of pure snow. Thus, BC effects on the single-scattering coalbedo of contaminated snow can vary with snow grain size and shape. For example, compared with fresh snow often with a shape of Koch snowflake and a size $\left(r_{v}\right)$ of $100 \mu \mathrm{m}$ (Erbe et al. 2003), old snow often with a shape of spheroid and a size $\left(r_{v}\right)$ of $1000 \mu \mathrm{m}$ (Dominé et al.
2003) has a higher single-scattering coalbedo, leading to a larger increase in snow single-scattering coalbedo when mixed with the same amount of BC particles. As a result, $\mathrm{BC}$ causes a larger reduction in the albedo of old snow relative to fresh snow due to combined shape and size effects, as revealed by previous studies (He et al. 2014; Liou et al.2014). This implies that snow grain shape and size both play important roles in BC-snow-radiation interactions and associated albedo effects.

\section{2) Parameterization of BC EFFeCts ON SNOW SINGLE-SCATTERING COALBEDO}

Based on the nonlinear regression, we find that the BC-induced $R_{1-\omega}$ of snow single-scattering coalbedo can be quantitatively related to $C_{\mathrm{BC}}$ in snow through the following equation:

$$
\log _{10}\left(R_{1-\omega}\right)=\log _{10}\left(d_{0}\right)+d_{1} \log _{10}\left(C_{\mathrm{BC}}+d_{2}\right)
$$

or, equivalently,

$$
R_{1-\omega}=d_{0}\left(C_{\mathrm{BC}}+d_{2}\right)^{d_{1}}
$$


(a) UV $(0.2-0.3 \mu \mathrm{m})$

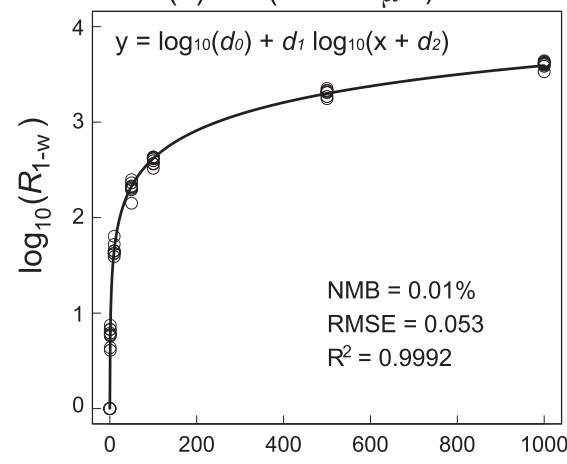

(b) VIS $(0.3-0.7 \mu \mathrm{m})$

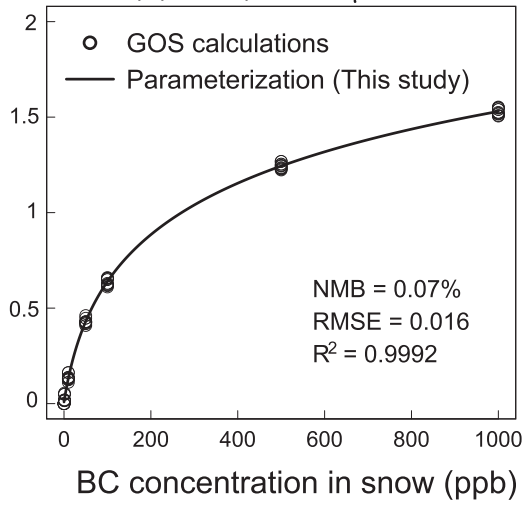

(c) NIR $(0.7-1.0 \mu \mathrm{m})$

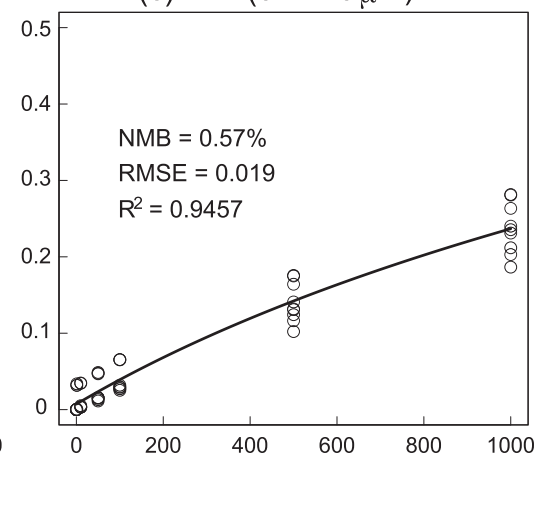

FIG. 7. The logarithm of BC-induced enhancement ratio of snow single-scattering coalbedo $\left[\log _{10}\left(R_{1-\omega}\right)\right.$ in Eq. (8a) $]$ as a function of BC concentration in snow at (a) UV, (b) VIS, and (c) NIR wavelength bands. Black circles are GOS calculations and black lines are fitting curves for a new parameterization [Eq. (8a)] from this study. Also shown are the mathematic formula, NMB, RMSE, and $R^{2}$ of the fitting curves. We note that the dots at each BC concentration scenario correspond to all the combinations of snow size and shape, with most of them overlapped with each other.

where $d_{i}$ (where $i=0-2$ ) is the wavelength-dependent parameterization coefficient. This parameterization well fits the GOS results at ultraviolet (UV; $0.2-0.3 \mu \mathrm{m}$ ), visible (VIS; $0.3-0.7 \mu \mathrm{m})$, and NIR $(0.7-1.0 \mu \mathrm{m})$ wavelengths (Fig. 7), with $R^{2}$ of $0.999,0.999$, and 0.946 and $\mathrm{NMB}$ of $0.01 \%, 0.07 \%$, and $0.57 \%$, respectively. We provide a dataset (Table 4 ) of these coefficients for three types of band divisions at wavelength $<\sim 1 \mu \mathrm{m}$, including a band type based on $\mathrm{Fu}$ (1996) (Fu96 band), a band type based on the Rapid Radiative Transfer Model (RRTM) (RRTM band), and a band type based on CLM (CLM band). Thus, our parameterization is ready for use in these models or other models with similar bands.

We find that the values of $d_{0}$ in Eq. (8b) are 1-3 orders of magnitude larger at $0.2-0.45 \mu \mathrm{m}$ than those at longer wavelengths, corresponding to the maximum BC-induced enhancement ratio of the snow single-scattering coalbedo at $0.2-0.4 \mu \mathrm{m}$ (Fig. 6). Although the values of $d_{2}$ are much larger at wavelengths $>0.5 \mu \mathrm{m}$ relative to those at shorter wavelengths, the effect is weakened by the decreasing values of $d_{1}$ at wavelengths $>0.5 \mu \mathrm{m}$. Figure 6 shows that the parameterization results match very well with the GOS calculations at different wavelengths for various $\mathrm{BC}$ concentrations in snow. Overall, the parameterization [Eq. (8b)] achieves a high accuracy for all the three band types (Fig. 8), with a $R^{2}$ of 0.999 , an NMB of $0.03 \%$, and an RMSE of 0.03 .

\section{Uncertainty analysis}

We conduct Monte Carlo computations to assess uncertainties in the snow single-scattering coalbedo and asymmetry factor in conjunction with snow grain size, grain shape, and $\mathrm{BC}$ contamination. For each factor (snow size, grain shape, or BC concentration), we use the present parameterizations to conduct 1000 calculations based on random sampling from the probability density function (PDF) of that factor when fixing the other factors and provide the $95 \%$ uncertainty range. We use the observed PDF of snow grain diameter (see Fig. S8 in the supplemental material) obtained from Nakamura et al. (2001), which follows the gamma distribution with number (count) means of 90 and $1500 \mu \mathrm{m}$ and standard deviations of 44 and $1072 \mu \mathrm{m}$ for fresh and old snow, respectively. The PDF of BC concentrations in snow (see Fig. S9 supplemental material), following a lognormal distribution with a geometric mean of $30 \mathrm{ppb}$ and a geometric standard deviation of 4.5 , is based on ground measurements over the Northern Hemispheric snowpack summarized in Qi et al. (2017a,b). We assume that snow grain shape follows a uniform distribution among the four shapes (i.e., Koch snowflake, hexagonal plate, spheroid, and sphere) used in this study.

Figure 9 shows the grain shape, grain size, and their combined effects on spectral single-scattering coalbedo of pure fresh and old snow. The snow grain shape has a very weak effect on fresh and old snow, leading to an uncertainty from $-18 \%$ to $+20 \%$. This, to some extent, justifies the treatment in Dang et al. (2016), who used single-scattering coalbedo of spherical snow grains to represent that of nonspherical snow grains. The grain size, however, shows a substantial impact on snow single-scattering coalbedo, resulting in uncertainties from $-91 \%$ to $+220 \%$ for fresh snow and from $-99 \%$ to $+480 \%$ for old snow. The size effect is weaker for fresh snow as a result of the relatively narrow size distribution of fresh snow (Fig. S8). The rather small 
TABLE 4. Coefficients for the parameterization [Eq. (8b)] of single-scattering coalbedo of BC-contaminated snow at ultraviolet, visible, and near-infrared wavelengths (UV-VIS-NIR). Three types of band divisions in UV-VIS-NIR wavelengths are used, including the Fu96, RRTM, and CLM band types (see text for details). BC has negligible effects on snow single-scattering coalbedo at wavelengths $>\sim 1 \mu \mathrm{m}$.

\begin{tabular}{|c|c|c|c|}
\hline $\begin{array}{l}\text { Wavelength } \\
\text { bands }^{\mathrm{a}}(\mu \mathrm{m})\end{array}$ & $d_{0}$ & $d_{1}$ & $d_{2}$ \\
\hline \multicolumn{4}{|c|}{ Fu96 band } \\
\hline $0.20-0.25$ & $2.48045 \times 10^{0}$ & $9.77209 \times 10^{-1}$ & $3.95960 \times 10^{-1}$ \\
\hline $0.25-0.30$ & $4.70305 \times 10^{0}$ & $9.73317 \times 10^{-1}$ & $2.04820 \times 10^{-1}$ \\
\hline $0.30-0.33$ & $4.68619 \times 10^{0}$ & $9.79650 \times 10^{-1}$ & $2.07410 \times 10^{-1}$ \\
\hline $0.33-0.36$ & $4.67369 \times 10^{0}$ & $9.84579 \times 10^{-1}$ & $2.09390 \times 10^{-1}$ \\
\hline $0.36-0.40$ & $4.65040 \times 10^{0}$ & $9.93537 \times 10^{-1}$ & $2.13030 \times 10^{-1}$ \\
\hline $0.40-0.44$ & $2.40364 \times 10^{0}$ & $9.95955 \times 10^{-1}$ & $4.18570 \times 10^{-1}$ \\
\hline $0.44-0.48$ & $7.95408 \times 10^{-1}$ & $9.95218 \times 10^{-1}$ & $1.29682 \times 10^{0}$ \\
\hline $0.48-0.52$ & $2.92745 \times 10^{-1}$ & $9.74284 \times 10^{-1}$ & $3.75514 \times 10^{0}$ \\
\hline $0.52-0.57$ & $8.63396 \times 10^{-2}$ & $9.81193 \times 10^{-1}$ & $1.27372 \times 10^{1}$ \\
\hline $0.57-0.64$ & $2.76299 \times 10^{-2}$ & $9.81239 \times 10^{-1}$ & $3.93293 \times 10^{1}$ \\
\hline $0.64-0.69$ & $1.40864 \times 10^{-2}$ & $9.55515 \times 10^{-1}$ & $8.78918 \times 10^{1}$ \\
\hline $0.69-0.75$ & $8.65705 \times 10^{-3}$ & $9.10491 \times 10^{-1}$ & $1.86969 \times 10^{2}$ \\
\hline $0.75-0.78$ & $6.12971 \times 10^{-3}$ & $8.74196 \times 10^{-1}$ & $3.45600 \times 10^{2}$ \\
\hline $0.78-0.87$ & $4.45697 \times 10^{-3}$ & $8.27238 \times 10^{-1}$ & $7.08637 \times 10^{2}$ \\
\hline $0.87-1.00$ & $3.06648 \times 10^{-2}$ & $4.82870 \times 10^{-1}$ & $1.41067 \times 10^{3}$ \\
\hline \multicolumn{4}{|c|}{ RRTM band } \\
\hline $0.200-0.263$ & $2.63506 \times 10^{0}$ & $9.76449 \times 10^{-1}$ & $3.72130 \times 10^{-1}$ \\
\hline $0.263-0.345$ & $4.68263 \times 10^{0}$ & $9.81055 \times 10^{-1}$ & $2.07970 \times 10^{-1}$ \\
\hline $0.345-0.442$ & $2.97002 \times 10^{0}$ & $9.93445 \times 10^{-1}$ & $3.36290 \times 10^{-1}$ \\
\hline $0.442-0.625$ & $7.04125 \times 10^{-2}$ & $9.90497 \times 10^{-1}$ & $1.50018 \times 10^{1}$ \\
\hline $0.625-0.778$ & $9.41066 \times 10^{-3}$ & $9.30711 \times 10^{-1}$ & $1.52704 \times 10^{2}$ \\
\hline $0.778-1.242$ & $3.21277 \times 10^{-1}$ & $1.69201 \times 10^{-1}$ & $9.01963 \times 10^{2}$ \\
\hline \multicolumn{4}{|c|}{ CLM band } \\
\hline $0.30-0.70$ & $3.50098 \times 10^{-2}$ & 9.91050 & $3.00370 \times 10^{1}$ \\
\hline $0.70-1.00$ & $6.51688 \times 10^{-3}$ & $7.36315 \times 10^{-1}$ & $9.52134 \times 10^{2}$ \\
\hline $1.00-1.20$ & $7.96544 \times 10^{-1}$ & $4.36649 \times 10^{-2}$ & $2.57288 \times 10^{2}$ \\
\hline
\end{tabular}

${ }^{\text {a }}$ Owing to negligible BC effects at wavelengths $>\sim 1 \mu \mathrm{m}$, bands at wavelengths $>1$ or $1.2 \mu \mathrm{m}$ for Fu96, RRTM, and CLM band types are not shown here.

uncertainty caused by grain size at a wavelength of $\sim 3 \mu \mathrm{m}$ is a result of a very strong snow absorption (i.e., a peak in snow imaginary index of refraction) at this wavelength (Warren and Brandt 2008).

On the other hand, the snow grain shape significantly affects asymmetry factor of both fresh and old snow, with a larger influence on fresh snow relative to old snow (Fig. 9). The shape effect is stronger at shorter wavelengths $(<\sim 1.8 \mu \mathrm{m})$. Jin et al. (2008) and Dang et al. (2016) also found that the differences in asymmetry factors between spherical snow grains and nonspherical counterparts are much larger at wavelengths $<2 \mu \mathrm{m}$ than that at longer wavelengths. We find that uncertainty in the asymmetry factor caused by grain size variation is negligible at wavelengths $<1 \mu \mathrm{m}$, while it becomes larger than that caused by the shape effect for old snow at wavelengths $>1 \mu \mathrm{m}$ (Fig. 9). The grain size leads to a very small variation in asymmetry factor for fresh snow, because of its narrow size distribution (Fig. S8). Therefore, snow shape effect dominates uncertainty in the asymmetry factor at wavelengths $<1 \mu \mathrm{m}$, whereas size effects become important at wavelengths $>1 \mu \mathrm{m}$.

Figure 10 shows the uncertainty in the spectral snow single-scattering coalbedo caused by $\mathrm{BC}$ contamination. The variation in $\mathrm{BC}$ concentration leads to a very large uncertainty in single-scattering coalbedo for both fresh and old snow at visible wavelengths but negligible at wavelengths $>1 \mu \mathrm{m}$, because of a weak (strong) snow absorption at visible (IR) wavelengths, which is the opposite for BC. The uncertainty decreases from 1-2 orders of magnitude at $0.2-0.4 \mu \mathrm{m}$ to between $-10 \%$ and $+50 \%$ at $0.8-1 \mu \mathrm{m}$. Thus, the single-scattering coalbedo of BC-contaminated snow predominantly varies with $\mathrm{BC}$ concentration in snow at visible wavelengths, followed by snow size, while snow size is the dominant factor at longer wavelengths.

\section{Notes on application of $\mathrm{BC}-$-snow parameterizations}

The parameterizations [Eqs. (4)-(8)] developed in this study account for snow grain shape, grain size, and $\mathrm{BC}$-snow internal mixing, which can be conveniently applied to snow models (e.g., SNICAR), land surface models (e.g., CLM), or climate models (e.g., CESM) including radiative transfer process (e.g., two-stream radiative transfer) throughout snowpack. As inputs to snow radiative transfer calculation, extinction efficiency, single-scattering coalbedo, and asymmetry factor of a $\mathrm{BC}-$-snow mixture are required. The spectral extinction efficiency can be computed from the Lorenz-Mie theory or geometric optics method by assuming spherical pure snow with the same projected area of its nonspherical counterpart or using the lookup tables (Tables S2-S4) provided in this study, because of negligible effects of grain shape and $\mathrm{BC}$ contamination on snow extinction efficiency. The spectral asymmetry factor, not affected by $\mathrm{BC}$ concentration in snow, can be computed from the parameterizations shown as Eqs. (6) and (7) to account for snow grain shape and size effects. The spectral single-scattering coalbedo of a $\mathrm{BC}-$ snow mixture is a function of all the three factors (i.e., shape, size, and BC concentration). Equation (4) is used to calculate the single-scattering coalbedo of pure snow, where size and shape effects are combined into the effective diameter. For snow grain structures (shape and aspect ratio) similar to those used in this study (see Table 1 and Fig. 1b), the effective diameter can be determined by the volumeequivalent sphere diameter and shape factor (Table 1). By combining Eqs. (4) and (8b), the single-scattering 


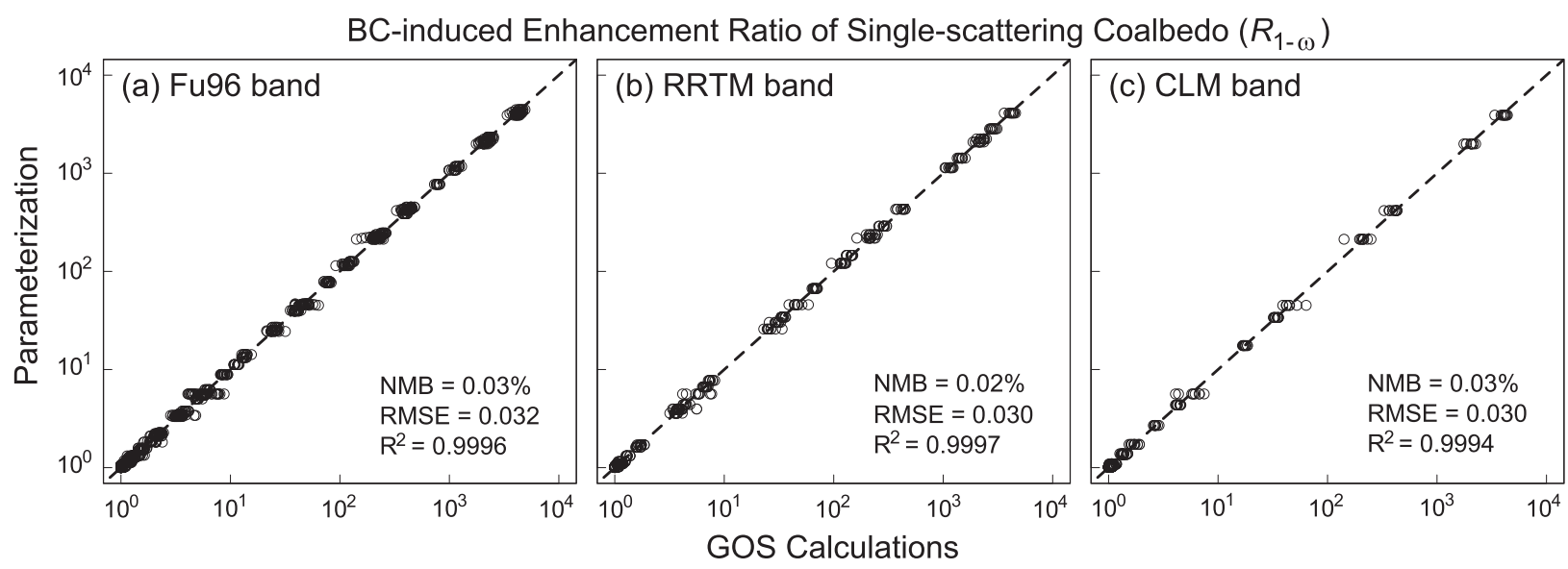

FIG. 8. Comparison for BC-induced enhancement ratio of snow single-scattering coalbedo $\left[R_{1-\omega}\right.$ in Eq. (8b)] from GOS calculations and a new parameterization [Eq. (8b)] from this study for three types of band divisions at 0.2-1.0- $\mu$ m wavelengths, including (a) the Fu96 band, (b) the RRTM band, and (c) the CLM band. See text and Table 4 for details. Also shown are the NMB, RMSE, and $R^{2}$.

coalbedo of BC-contaminated snow can be obtained. We should note that Eq. (8b) is only for BC-snow internal mixing, while Eqs. (4)-(7) work for both internal and external mixing of BC and snow. We also note that, in our parameterizations, snow shape information is implicitly included in two key parameters, $D_{e}$ and $f_{s, x}$.
Thus, the parameterization coefficients (see Tables 2-4) for each snow single-scattering property are the same for different shapes. Furthermore, our results suggest that it is important to take into account nonspherical snow shapes in climate models. Based on observations (e.g., Dominé et al. 2003), Koch snowflake and spheroid (a) Snow Shape Effect
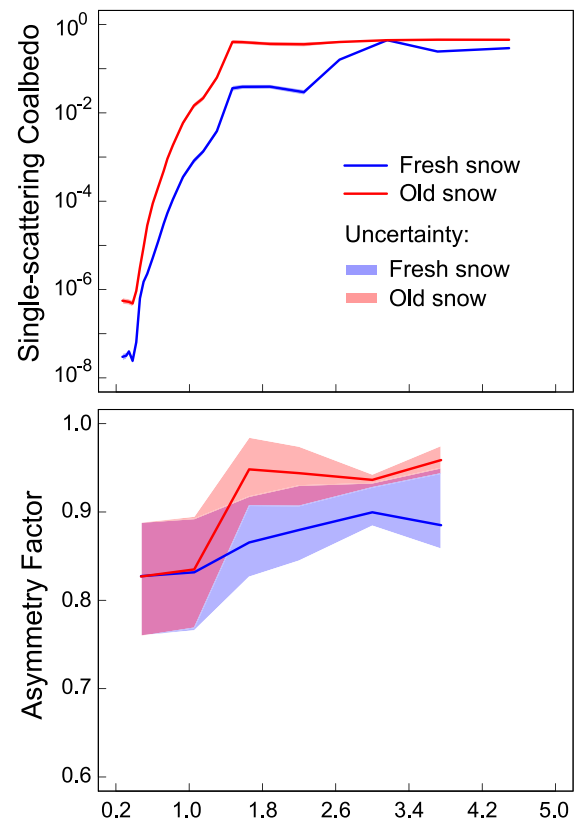

(b) Snow Size Effect
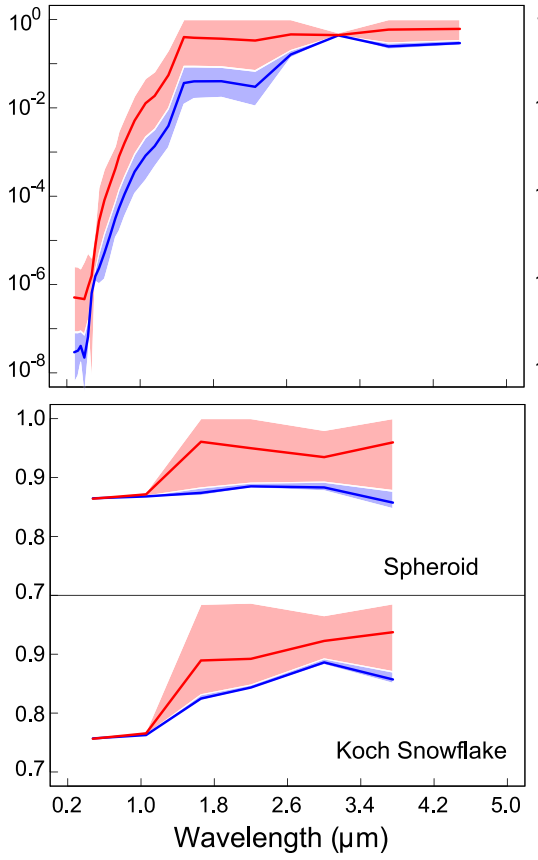

(c) Combined Effects
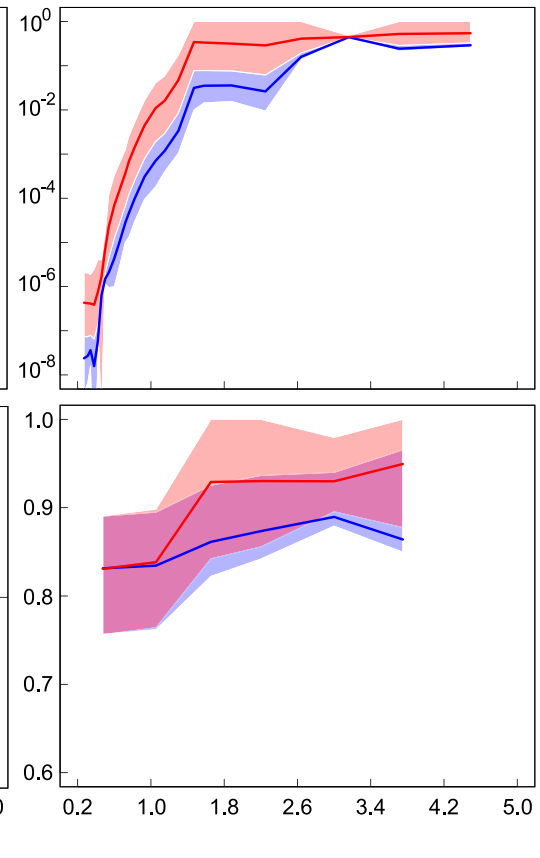

FIG. 9. (top) Spectral single-scattering coalbedo and (bottom) asymmetry factor of fresh (blue) and old (red) clean snow due to (a) snow shape effect by varying grain shapes (i.e., sphere, Koch snowflake, spheroid, or hexagonal plate), (b) snow size effect by varying grain sizes, and (c) combined effects by varying grain shapes and sizes together. Solid lines are medians and shaded areas are $95 \%$ uncertainty ranges. The probability density distributions of fresh and old snow grain sizes (see Fig. S8) are based on observations from Nakamura et al. (2001). The results are based on the Monte Carlo calculations using the parameterizations developed in this study. Note that the uncertainties (shaded areas) for fresh and old snow in the top panel of (a) are very small. 


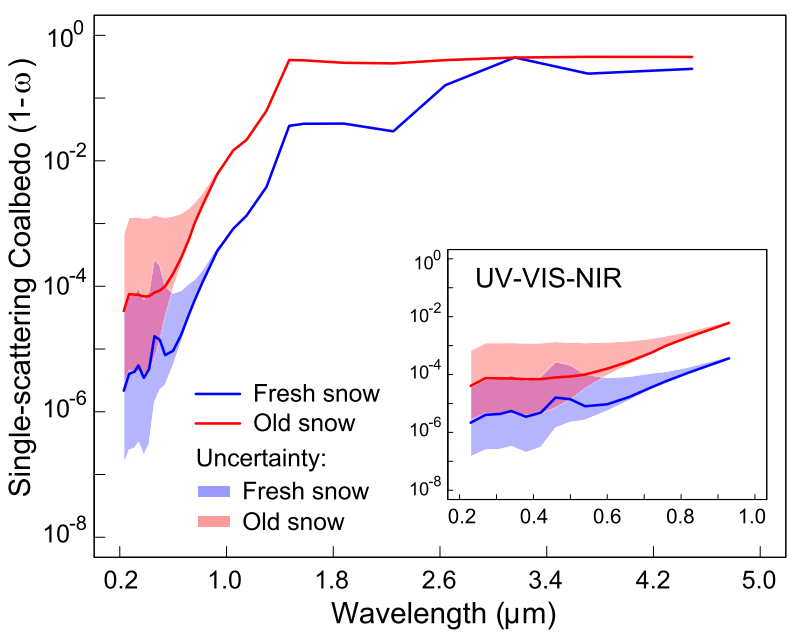

FIG. 10. Spectral single-scattering coalbedo $(1-\omega)$ of fresh (blue) and old (red) snow resulting from BC contamination effect by varying $\mathrm{BC}$ concentrations in snow. Solid lines are medians and shaded areas are $95 \%$ uncertainty ranges. The probability density distributions of fresh and old snow grain sizes (see Fig. S8) are based on observations from Nakamura et al. (2001). The probability density distributions of $\mathrm{BC}$ concentration in snow (see Fig. S9) are based on observations over the Northern Hemispheric snowpack summarized in Qi et al. (2017a,b). The results are based on the Monte Carlo calculations using the parameterization [Eqs. (4) and (8b)] in this study. Also shown in the inset panel is a zoom in for ultraviolet, visible, and near-infrared wavelengths (UV-VISNIR; $0.2-1.0 \mu \mathrm{m})$. Note that snow grain shape is not specified, because of its negligible effect on single-scattering coalbedo.

appear to be reasonable assumptions for fresh and old snow grain shapes, respectively, for climate modeling.

In this study, we consider snow grain diameters of up to $2000 \mu \mathrm{m}$ and $\mathrm{BC}$ concentrations of up to $1000 \mathrm{ppb}$, which covers the majority of conditions in real snowpack (LaChapelle 1969; Qian et al. 2015). For situations with extremely large snow grains $\left(D_{e}>2000 \mu \mathrm{m}\right)$ and/or severe $\mathrm{BC}$ contamination in snow $\left(C_{\mathrm{BC}}>1000 \mathrm{ppb}\right)$, the parameterizations developed in this study should be used with caution. We also realize that, ideally, a more useful and robust parameterization should depend functionally on wavelength, which will be investigated in future work.

In addition, for land surface and/or climate models without snowpack radiative transfer schemes, a parameterization that directly relates snow albedo, rather than the single-scattering properties, to snow grain size, shape, and $\mathrm{BC}$ concentration in snow are required. Recently, Dang et al. (2015) have developed a parameterization for $\mathrm{BC}$ externally mixed with snow spheres, where snow albedo reduction is a function of $\mathrm{BC}$ concentration and snow effective size. On this basis, Dang et al. (2016) further provided a scaling factor for snow albedo to account for the nonspherical shape effect. To go one step further, our companion work (C. He et al. 2017, manuscript submitted to J. Geophys. Res. Atmos.) has developed a new snow albedo parameterization that explicitly accounts for BC-snow internal mixing and nonspherical snow grains, directly linking $\mathrm{BC}$-induced snow albedo reduction and associated radiative effects with snow grain properties and $\mathrm{BC}$ concentration in snow.

\section{Conclusions}

We have developed a set of parameterizations for the spectral single-scattering coalbedo and asymmetry factor of both clean and BC-contaminated snow based on the GOS computations, which explicitly resolves BCsnow internal mixing and snow grain shapes (i.e., Koch snowflake, hexagonal plate, spheroid, and sphere). We further analyzed the uncertainty in the parameterized snow single-scattering properties contributed by snow grain size, shape, and BC concentration in snow. Finally, we showed the manner in which the present parameterizations can be applied to climate models that are coupled with land surface models involving snow.

We found that the single-scattering coalbedo of pure snow increased from visible to IR wavelengths by several orders of magnitude, because of the spectral characteristics of snow imaginary index of refraction. Larger snow grains had higher single-scattering coalbedos than smaller grains by up to one order of magnitude, particularly at wavelengths $<2.5 \mu \mathrm{m}$. Our results showed that the snow single-scattering coalbedo is predominantly affected by grain sizes, rather than grain shapes. Following the formulations in Liou et al. (2013) and $\mathrm{Fu}$ (1996), we parameterized the snow single-scattering coalbedo as a function of effective grain diameter that contains shape and size information. This parameterization showed an overall accuracy of $>99 \%$.

We found that snow grain size had a very small impact on the asymmetry factor at wavelengths $<1 \mu \mathrm{m}$. Compared with nonspherical grains, snow spheres with the same volume had up to $20 \%$ larger asymmetry factors and hence stronger forward scattering at wavelengths $<\sim 2.6 \mu \mathrm{m}$, with $<2 \%$ differences at longer wavelengths. By extending the formulation in $\mathrm{Fu}$ (2007), we developed a new parameterization for snow asymmetry factor by including an additional grain shape factor. This parameterization closely captured the GOS results, exhibiting an improvement relative to Fu's (2007) parameterization for application to nonspherical snow grains.

We showed that BC-snow internal mixing did not alter the snow asymmetry factor, whereas it significantly enhanced the snow single-scattering coalbedo at wavelengths $<1 \mu \mathrm{m}$, particularly at visible wavelengths. 
The BC-induced enhancement ratio of single-scattering coalbedo was only affected by the $\mathrm{BC}$ concentration in snow, but independent of snow grain size and shape. We parameterized the enhancement ratio as a function of BC concentration, which showed a high accuracy with a $R^{2}$ of 0.999 and an NMB of $0.03 \%$.

Based on Monte Carlo computations, uncertainty in the parameterized single-scattering coalbedo of pure snow was predominantly contributed by variation in snow grain size, rather than grain shape. In contrast, the grain shape effect dominated uncertainty in the asymmetry factor at wavelengths $<1 \mu \mathrm{m}$, whereas the grain size effect was important at wavelengths $>1 \mu \mathrm{m}$. Uncertainty in the snow single-scattering coalbedo caused by variation in the $\mathrm{BC}$ concentration could be as high as $1-2$ orders of magnitude at $0.2-0.4 \mu \mathrm{m}$.

Overall, both $\mathrm{BC}-$-snow internal mixing and snow grain shape play critically important roles in quantifying BC effects on snow optical properties. Our results suggested that assuming only spherical snow grains in models could introduce biases in estimates of BCinduced snow albedo effects, making a simultaneous consideration of the two factors a necessity in climate modeling. The parameterizations developed in this study can be readily applied to snow, land surface, and/or climate models with radiative transfer schemes throughout snowpack.

Acknowledgments. The authors thank the two reviewers for their helpful comments. This study was supported by NSF Grant AGS-1523296. The authors thank L. Qi for providing the data of BC concentration in snow and C. Dang for helpful discussions. Users can access the data used in this study via the corresponding author without any restrictions. The authors declare no conflicts of interest.

\section{REFERENCES}

Aoki, T., K. Kuchiki, M. Niwano, Y. Kodama, M. Hosaka, and T. Tanaka, 2011: Physically based snow albedo model for calculating broadband albedos and the solar heating profile in snowpack for general circulation models. J. Geophys. Res., 116, D11114, https://doi.org/10.1029/2010JD015507.

Bond, T. C., and R. W. Bergstrom, 2006: Light absorption by carbonaceous particles: An investigative review. Aerosol Sci. Technol., 40, 27-67, https://doi.org/10.1080/02786820500421521.

— , and Coauthors, 2013: Bounding the role of black carbon in the climate system: A scientific assessment. J. Geophys. Res. Atmos., 118, 5380-5552, https://doi.org/10.1002/jgrd.50171.

COESA, 1976: U. S. Standard Atmosphere, 1976. NOAA, 227 pp., http://ntrs.nasa.gov/archive/nasa/casi.ntrs.nasa.gov/19770009539_ 1977009539.pdf.

Dang, C., R. E. Brandt, and S. G. Warren, 2015: Parameterizations for narrowband and broadband albedo of pure snow and snow containing mineral dust and black carbon. J. Geophys. Res. Atmos., 120, 5446-5468, https://doi.org/10.1002/2014JD022646.
- Q. Fu, and S. G. Warren, 2016: Effect of snow grain shape on snow albedo. J. Atmos. Sci., 73, 3573-3583, https://doi.org/ 10.1175/JAS-D-15-0276.1.

Dominé, F., T. Lauzier, A. Cabanes, L. Legagneux, W. F. Kuhs, K. Techmer, and T. Heinrichs, 2003: Snow metamorphism as revealed by scanning electron microscopy. Microsc. Res. Tech., 62, 33-48, https://doi.org/10.1002/jemt.10384.

Dutra, E., G. Balsamo, P. Viterbo, P. M. A. Miranda, A. Beljaars, C. Schär, and K. Elder, 2010: An improved snow scheme for the ECMWF land surface model: Description and offline validation. J. Hydrometeor., 11, 899-916, https://doi.org/ 10.1175/2010JHM1249.1.

Erbe, E. F., A. Rango, J. Foster, E. G. Josberger, C. Pooley, and W. P. Wergin, 2003: Collecting, shipping, storing, and imaging snow crystals and ice grains with low-temperature scanning electron microscopy. Microsc. Res. Tech., 62, 19-32, https:// doi.org/10.1002/jemt.10383.

Flanner, M. G., C. S. Zender, J. T. Randerson, and P. J. Rasch, 2007: Present-day climate forcing and response from black carbon in snow. J. Geophys. Res., 112, D11202, https://doi.org/ 10.1029/2006JD008003.

- - - P. G. Hess, N. M. Mahowald, T. H. Painter, V. Ramanathan, and P. J. Rasch, 2009: Springtime warming and reduced snow cover from carbonaceous particles. Atmos. Chem. Phys., 9, 2481-2497, https://doi.org/10.5194/acp-9-2481-2009.

— X. Xiu, C. Zhou, J. E. Penner, and C. Jiao, 2012: Enhanced solar energy absorption by internally-mixed black carbon in snow grains. Atmos. Chem. Phys., 12, 4699-4721, https:// doi.org/10.5194/acp-12-4699-2012.

Foot, J. S., 1988: Some observations of the optical properties of clouds. II: Cirrus. Quart. J. Roy. Meteor. Soc., 114, 145-164, https://doi.org/10.1002/qj.49711447908.

Frei, A., M. Tedesco, S. Lee, J. Foster, D. K. Hall, R. Kelly, and D. A. Robinson, 2012: A review of global satellite-derived snow products. Adv. Space Res., 50, 1007-1029, https://doi.org/ 10.1016/j.asr.2011.12.021.

Fu, Q., 1996: An accurate parameterization of the solar radiative properties of cirrus clouds for climate models. J. Climate, $\mathbf{9}$, 2058-2082, https://doi.org/10.1175/1520-0442(1996)009<2058: AAPOTS $>2.0 . \mathrm{CO} ; 2$.

- 2007: A new parameterization of an asymmetry factor of cirrus clouds for climate models. J. Atmos. Sci., 64, 4140-4150, https://doi.org/10.1175/2007JAS2289.1.

— W. W. Bun, and P. Yang, 1999: Modeling of scattering and absorption by nonspherical cirrus ice particles at thermal infrared wavelengths. J. Atmos. Sci., 56, 2937-2947, https:// doi.org/10.1175/1520-0469(1999)056<2937:MOSAAB > 2.0.CO;2.

Gardner, A. S., and M. J. Sharp, 2010: A review of snow and ice albedo and the development of a new physically based broadband albedo parameterization. J. Geophys. Res., 115, F01009, https://doi.org/10.1029/2009JF001444.

Garrett, T. J., S. E. Yuter, C. Fallgatter, K. Shkurko, S. R. Rhodes, and J. L. Endries, 2015: Orientations and aspect ratios of falling snow. Geophys. Res. Lett., 42, 4617-4622, https:// doi.org/10.1002/2015GL064040.

Grenfell, T. C., S. P. Neshyba, and S. G. Warren, 2005: Representation of a nonspherical ice particle by a collection of independent spheres for scattering and absorption of radiation: 3. Hollow columns and plates. J. Geophys. Res., 110, D17203, https://doi.org/10.1029/2005JD005811.

Gueymard, C. A., D. Myers, and K. Emery, 2002: Proposed reference irradiance spectra for solar energy systems testing. Sol. Energy, 73, 443-467, https://doi.org/10.1016/S0038-092X(03)00005-7. 
Hansen, J. E., and L. Nazarenko, 2004: Soot climate forcing via snow and ice albedos. Proc. Natl. Acad. Sci. USA, 101, 423428, https://doi.org/10.1073/pnas.2237157100.

He, C., Q. Li, K.-N. Liou, Y. Takano, Y. Gu, L. Qi, Y. Mao, and L. R. Leung, 2014: Black carbon radiative forcing over the Tibetan Plateau. Geophys. Res. Lett., 41, 7806-7813, https:// doi.org/10.1002/2014GL062191.

, K.-N. Liou, Y. Takano, R. Zhang, M. Levy Zamora, P. Yang, Q. Li, and L. R. Leung, 2015: Variation of the radiative properties during black carbon aging: Theoretical and experimental intercomparison. Atmos. Chem. Phys., 15, 11967 11 980, https://doi.org/10.5194/acp-15-11967-2015.

_ , Y. Takano, K.-N. Liou, P. Yang, Q. Li, and D. W. Mackowski, 2016: Intercomparison of the GOS approach, superposition T-matrix method, and laboratory measurements for black carbon optical properties during aging. J. Quant. Spectrosc. Radiat. Transfer, 184, 287-296, https://doi.org/10.1016/ j.jqsrt.2016.08.004.

,-- , and -2017 : Close packing effects on clean and dirty snow albedo and associated climatic implications. Geophys. Res. Lett., 44, 3719-3727, https://doi.org/10.1002/2017GL072916.

Jacobson, M. Z., 2004: Climate response of fossil fuel and biofuel soot, accounting for soot's feedback to snow and sea ice albedo and emissivity. J. Geophys. Res., 109, D21201, https://doi.org/ 10.1029/2004JD004945.

Jin, Z., T. P. Charlock, P. Yang, Y. Xie, and W. Miller, 2008: Snow optical properties for different particle shapes with application to snow grain size retrieval and MODIS/CERES radiance comparison over Antarctic. Remote Sens. Environ., 112, 35633581, https://doi.org/10.1016/j.rse.2008.04.011.

Krekov, G. M., 1993: Models of atmospheric aerosols. Aerosol Effects on Climate, S. G. Jennings, Ed., University of Arizona Press, 9-72.

LaChapelle, E. R., 1969: Field Guide to Snow Crystals. University of Washington Press, $101 \mathrm{pp}$.

Lee, W.-L., K. N. Liou, C. He, H.-C. Liang, T.-C. Wang, Q. Li, Z. Liu, and Q. Yue, 2017: Impact of absorbing aerosol deposition on snow albedo reduction over the southern Tibetan Plateau based on satellite observations. Theor. Appl. Climatol., 129, 1373-1382, https://doi.org/10.1007/s00704-016-1860-4.

Li, Z., and Coauthors, 2017: A potential large and persistent black carbon forcing over northern Pacific inferred from satellite observations. Sci. Rep., 7, 43429, https://doi.org/10.1038/srep43429.

Liou, K. N., 2002: Principle of geometric optics for application to light scattering by ice crystals. An Introduction to Atmospheric Radiation, 2nd ed. Academic Press, 176-250.

_- and P. Yang, 2016: Light scattering by atmospheric particulates. Light Scattering by Ice Crystals: Fundamentals and Applications, Cambridge University Press, 168-173.

__, Y. Takano, and P. Yang, 2011: Light absorption and scattering by aggregates: Application to black carbon and snow grains. J. Quant. Spectrosc. Radiat. Transfer, 112, 1581-1594, https://doi.org/10.1016/j.jqsrt.2011.03.007.

,,-- Q. Yue, and P. Yang, 2013: On the radiative forcing of contrail cirrus contaminated by black carbon. Geophys. Res. Lett., 40, 778-784, https://doi.org/10.1002/grl.50110.

, C. He, P. Yang, L. R. Leung, Y. Gu, and W. L. Lee, 2014: Stochastic parameterization for light absorption by internally mixed $\mathrm{BC} / \mathrm{dust}$ in snow grains for application to climate models. J. Geophys. Res. Atmos., 119, 7616-7632, https:// doi.org/10.1002/2014JD021665.

Magono, C., T. Endoh, F. Ueno, S. Kubota, and M. Itasaka, 1979: Direct observations of aerosols attached to falling snow crystals. Tellus, 31, 102-114, https://doi.org/10.3402/tellusa. v31i2.10415.

Marshall, S. E., and S. G. Warren, 1987: Parameterization of snow albedo for climate models. Large Scale Effects of Seasonal Snow Cover, B. E. Goodison, R. G. Barry, and J. Dozier, Eds., IAHS Publ. 166, 43-50.

Menon, S., D. Koch, G. Beig, S. Sahu, J. Fasullo, and D. Orlikowski, 2010: Black carbon aerosols and the third polar ice cap. Atmos. Chem. Phys., 10, 4559-4571, https://doi.org/ 10.5194/acp-10-4559-2010.

Mitchell, D. L., A. Macke, and Y. G. Liu, 1996: Modeling cirrus clouds. Part II: Treatment of radiative properties. J. Atmos. Sci., 53, 2967-2988, https://doi.org/10.1175/1520-0469(1996)053<2967: MCCPIT $>2.0 . \mathrm{CO} ; 2$.

Nakamura, T., O. Abe, T. Hasegawa, R. Tamura, and T. Ohta, 2001: Spectral reflectance of snow with a known grain-size distribution in successive metamorphism. Cold Reg. Sci. Technol., 32, 13-26, https://doi.org/10.1016/S0165-232X(01)00019-2.

Neshyba, S. P., T. C. Grenfell, and S. G. Warren, 2003: Representation of a nonspherical ice particle by a collection of independent spheres for scattering and absorption of radiation: 2. Hexagonal columns and plates. J. Geophys. Res., 108, 4448, https://doi.org/10.1029/2002JD003302.

Niu, G.-Y., and Coauthors, 2011: The community Noah land surface model with multiparameterization options (Noah-MP): 1. Model description and evaluation with local-scale measurements. J. Geophys. Res., 116, D12109, https://doi.org/10.1029/ 2010JD015139.

Painter, T. H., N. P. Molotch, M. Cassidy, M. Flanner, and K. Steffen, 2007: Instruments and methods: Contact spectroscopy for determination of stratigraphy of snow optical grain size. J. Glaciol., 53, 121-127, https://doi.org/10.3189/ 172756507781833947

, M. G. Flanner, G. Kaser, B. Marzeion, R. A. VanCuren, and W. Abdalati, 2013: End of the Little Ice Age in the Alps forced by industrial black carbon. Proc. Natl. Acad. Sci. USA, 110, 15 216-15 221, https://doi.org/10.1073/pnas.1302570110.

Qi, L., Q. Li, Y. Li, and C. He, 2017a: Factors controlling black carbon distribution in the Arctic. Atmos. Chem. Phys., 17, 1037-1059, https://doi.org/10.5194/acp-17-1037-2017.

- - C. He, X. Wang, and J. Huang, 2017b: Effects of the Wegener-Bergeron-Findeisen process on global black carbon distribution. Atmos. Chem. Phys., 17, 7459-7479, https://doi.org/10.5194/acp-17-7459-2017.

Qian, Y., W. I. Gustafson Jr., L. R. Leung, and S. J. Ghan, 2009: Effects of soot-induced snow albedo change on snowpack and hydrological cycle in western United States based on Weather Research and Forecasting chemistry and regional climate simulations. J. Geophys. Res., 114, D03108, https://doi.org/ 10.1029/2008JD011575.

, and Coauthors, 2015: Light-absorbing particles in snow and ice: Measurement and modeling of climatic and hydrological impact. Adv. Atmos. Sci., 32, 64-91, https://doi.org/10.1007/ s00376-014-0010-0

Qu, X., and A. Hall, 2014: On the persistent spread in snow-albedo feedback. Climate Dyn., 42, 69-81, https://doi.org/10.1007/ s00382-013-1774-0.

Schwarz, J. P., R. S. Gao, A. E. Perring, J. R. Spackman, and D. W. Fahey, 2013: Black carbon aerosol size in snow. Sci. Rep., 3, 1356, https://doi.org/10.1038/srep01356.

Takala, M., K. Luojus, J. Pulliainen, C. Derksen, J. Lemmetyinen, J.-P. Kärnä, J. Koskinen, and B. Bojkov, 2011: Estimating Northern Hemisphere snow water equivalent for climate 
research through assimilation of space-borne radiometer data and ground-based measurements. Remote Sens. Environ., 115, 3517-3529, https://doi.org/10.1016/j.rse.2011.08.014.

Takano, Y., K. N. Liou, M. Kahnert, and P. Yang, 2013: The singlescattering properties of black carbon aggregates determined from the geometric-optics surface-wave approach and the T-matrix method. J. Quant. Spectrosc. Radiat. Transfer, 125, 51-56, https://doi.org/10.1016/j.jqsrt.2013.04.006.

Warren, S. G., 1982: Optical properties of snow. Rev. Geophys., 20, 67-89, https://doi.org/10.1029/RG020i001p00067.

_- and W. J. Wiscombe, 1980: A model for the spectral albedo of snow. II: Snow containing atmospheric aerosols. J. Atmos. Sci., 37, 2734-2745, https://doi.org/10.1175/1520-0469(1980)037<2734: AMFTSA $>2.0 . \mathrm{CO} ; 2$.

- and - 1985: Dirty snow after nuclear-war. Nature, 313, 467-470, https://doi.org/10.1038/313467a0.

, and R. E. Brandt, 2008: Optical constants of ice from the ultraviolet to the microwave: A revised compilation.
J. Geophys. Res., 113, D14220, https://doi.org/10.1029/ 2007JD009744.

Wiscombe, W. J., and S. G. Warren, 1980: A model for the spectral albedo of snow: I. Pure snow. J. Atmos. Sci., 37, 2712-2733, https://doi.org/10.1175/1520-0469(1980)037<2712: AMFTSA $>2.0 . \mathrm{CO} ; 2$.

$\mathrm{Xu}, \mathrm{B}$. Q., and Coauthors, 2009: Black soot and the survival of Tibetan glaciers. Proc. Natl. Acad. Sci. USA, 106, 22114 22 118, https://doi.org/10.1073/pnas.0910444106.

Yang, P., and K. N. Liou, 1997: Light scattering by hexagonal ice crystals: Solutions by a ray-by-ray integration algorithm. J. Opt. Soc. Amer., 14, 2278-2289, https://doi.org/10.1364/ JOSAA.14.002278.

Zege, E., I. Katsev, A. Malinka, A. Prikhach, and I. Polonsky, 2008: New algorithm to retrieve the effective snow grain size and pollution amount from satellite data. Ann. Glaciol., 49, 139-144, https://doi.org/10.3189/ 172756408787815004 . 